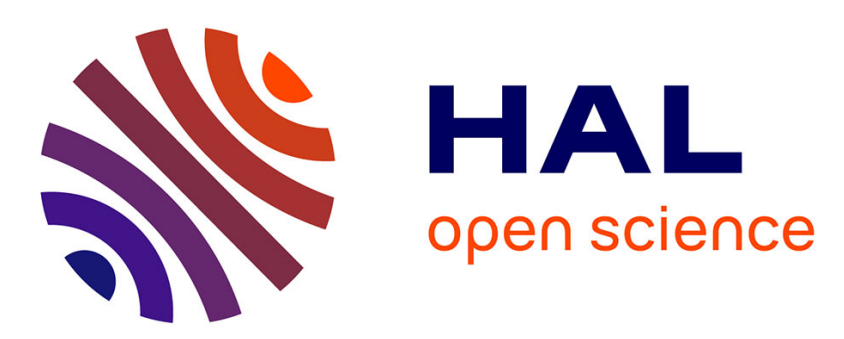

\title{
In situ Fourier-Transform infrared spectroscopy studies of inorganic ions adsorption on metal oxides and hydroxides
}

Grégory Lefèvre

\section{To cite this version:}

Grégory Lefèvre. In situ Fourier-Transform infrared spectroscopy studies of inorganic ions adsorption on metal oxides and hydroxides. 2003. hal-00000940

\section{HAL Id: hal-00000940 \\ https://hal.science/hal-00000940}

Preprint submitted on 11 Dec 2003

HAL is a multi-disciplinary open access archive for the deposit and dissemination of scientific research documents, whether they are published or not. The documents may come from teaching and research institutions in France or abroad, or from public or private research centers.
L'archive ouverte pluridisciplinaire HAL, est destinée au dépôt et à la diffusion de documents scientifiques de niveau recherche, publiés ou non, émanant des établissements d'enseignement et de recherche français ou étrangers, des laboratoires publics ou privés. 


\title{
IN SITU FOURIER-TRANSFORM INFRARED SPECTROSCOPY STUDIES OF INORGANIC IONS ADSORPTION ON METAL OXIDES AND HYDROXIDES
}

\author{
G. Lefèvre \\ Centre d'Etudes de Chimie Métallurgique CNRS-UPR 2801 \\ 15, Rue Georges Urbain F94407 Vitry/Seine \\ France
}

lefevre@glvt-cnrs.fr

Fax: 33-1-46-75-04-33

\begin{abstract}
In this work, the studies describing the use of attenuated total reflection - infrared spectroscopy to obtain information on the sorption mechanism of inorganic ions on metal oxy-hydroxides are reviewed. ATR-IR is amongst the rare techniques which allow to analyze the sorption phenomena in situ and led to several results about the speciation of sorbed anions (sulfate, carbonate, phosphate, perchlorate, ...) or ternary inorganic complexes since it is able to distinguish outer-sphere and inner-sphere complexes. The principles of this method are summarized, and the experimental protocols, the results and the limitations are detailed. The sample deposition method, initially based a paste or a concentrated suspension, have evolved towards the coating of the ATR crystal by a colloid layer, increasing the sensibility and the reproducibility of the measurements. Observed absorption frequencies of ions sorbed on metal oxy-hydroxides (goethite, hematite, alumina, silica, $\mathrm{TiO}_{2}, \ldots$ ) are reported to help the identification of peaks in new experimental works. This method, characterized by an in situ analysis performed with a special cell used in a widespread instrumentation (IR spectrometer), is very recent but its advantages suitable for the current problems in the sorption field should help its rapid development for the next years.
\end{abstract}

ATR-IR; surface complexation; review; oxides, hydroxides; sorption 


\section{INTRODUCTION}

Sorption of inorganic ions on solid matter plays a major role in several fields such as catalysis, transport of toxic species in natural waters, and decontamination of liquid wastes. The long-term safety of radioactive waste depositories is based on the sorption of radionuclides on engineered and natural barriers placed around the depositories. In order to predict the safety of such depositories in very long term, it is necessary to extrapolate sorption data, measured on reference systems at the laboratory scale, to real systems and over very long times. Thus the extrapolation of data measured in laboratory studies must be performed through models based on physico-chemical processes as close as possible to the real ones. If a process that may become important at a certain moment is ill modeling or forgetting, the longterm prediction may turns out to be wrong. Thus, the determination and modeling of the sorption mechanisms, connected to the long-term safety of radioactive waste depositories, has become a great challenge.

Several methods of modeling sorption data have been developed. The simplest one is the measurement of the distribution coefficient $\left(\mathrm{K}_{\mathrm{D}}\right)$ of ions between the solution and a mineral, and the further use of $K_{D}$ data banks to calculate the retardation factors of radionuclides during the water transport. However, since $K_{D}$ values depend on many factors, this method is very hazardous. Modeling of adsorption isotherms by Langmuir equations allows calculating an affinity constant $\left(\mathrm{K}_{\mathrm{ads}}\right)$ [1]. At low concentrations, $\mathrm{K}_{\mathrm{ads}}$ is related with $\mathrm{K}_{\mathrm{D}}$ by the formula $\mathrm{K}_{\mathrm{D}}=\mathrm{K}_{\mathrm{ads}} \times \mathrm{c}_{\max }$ where $\mathrm{c}_{\max }$ is the maximum surface concentration (mol/kg). Other models are used to fit experimental adsorption isotherms, in order to take into account lateral interactions (Frumkin equation) or heterogeneous surface properties (Freundlich equation) [1]. The surface complexation models, based on chemical and electrostatic processes at the solid-water interface, would be a better way to quantify the sorption processes. However, the choice between several surface complexation models (1-pK or 2-pK monosite models, 1-pK multisite 
model), together with the choice of the right electrostatic model [2,3], are still a matter of a large debate. These problems will not be detailed in this review, which deals with another important information: the nature of species sorbed at the water-solid interface. The surface speciation is of the utmost importance when determining thermodynamic surface complexation constants. Differentiating between inner- (IS) and outer-sphere (OS) complexes has been often made by observing the effect of ionic strength on the quantity of sorbed ions. However, this method has been questioned in several papers [4,5], pointing out the need of spectroscopic methods to solve this problem. The fitting of experimental data, as the sorbed fraction of ions versus $\mathrm{pH}$, has been used to determine both the surface inner-sphere complex structure (typically monodentate or bidentate) and the thermodynamic complexation constant [3]. However, due to the number of adjustable parameters (sites density, acidity constants, surface complexation constants, electrostatic parameters,...), such a method often led to several sets of surface complexes [3] and spectroscopic results may be of invaluable help for determining the nature of surface complexes.

Ex-situ spectroscopic methods have been used to characterize the surfaces of metallic oxy-hydroxides after sorption. X-ray photoelectron spectroscopy (XPS) brings information on the oxidation state of the sorbed ions (which can be different from the solute species if a redox reaction occurs [6]), and may distinguish different surface complexes through the shift of the binding energy for ions such as uranyl [7], but this method is not efficient for most of the elements due to the small variations in the chemical environment of elements induced by the surface complexation. Moreover, this method is performed inside a high vacuum chamber, and dehydration may modify the structure of surface complexes.

X-ray absorption spectroscopy (XANES, EXAFS) is the most widespread technique used to investigate the surface complexes geometry on wet samples. The determination of coordination numbers of the sorbed ion and radial distances of the shells surrounding it have 
led to interesting results, for instance on goethite reactivity towards $\mathrm{Se}[5]$ or $\mathrm{Pb}[8]$, or on the reactivity of alumina surface towards As [9], Cd [10] or Se [10].

Due to its ability to probe chemical bonds, infrared spectroscopy has been applied for years to sorption studies. The first studies made use of invasive sampling techniques, in which dried compacted powders (transmission spectra) or mixtures with $\mathrm{KBr}$ (diffuse reflectance spectra: DRIFT) were analyzed. Drying samples has been suggested to favoring the conversion of monodentate to bidentate complexes of sulfate $[11,12]$, whereas Sugimoto and Wang [13] attributed this behavior to a $\mathrm{pH}$ drop during the drying process. Moreover, dilution in $\mathrm{KBr}$ in presence of trace of wetness would result in $\mathrm{pH}$ shifting towards neutral values [11], converting IS sulfate sorbed at low $\mathrm{pH}$ values to OS complex. Since ions might be coordinated differently with dried and wet surfaces, FTIR measurements in the presence of water are needed. The problem of the strong IR absorption by water could be believed as irresolvable. This problem can be solved by using internal reflection spectroscopy, i.e. by probing a short depth of sample by the evanescent wave existing in a lower index refraction medium (water) in contact with a more dense medium in which an IR radiation is propagating [14]. This spectroscopic technique, called attenuated total reflection (ATR), was firstly applied to the sorption of organic molecules onto suspensions in relation with flotation process [15], but several factors, as the impact of surface charge on dispersitivity, complicates quantitative measurements in suspensions with changing parameters ( $\mathrm{pH}$, adsorbate concentration, ionic strength). Its use to characterize the surface complexes of inorganic ions sorbed onto oxides has gained advantage from the procedure developed by Hug and Sulzberger $[12,16]$ who coated the ATR element by a layer of colloidal mineral particles, allowing a quantitative spectral analysis.

This review will address the current state of knowledge in the use of FTIR-ATR to determine surface complexes between inorganic ions and oxides/hydroxides surfaces. Several 
more general reviews about ATR have previously been published $[15,17,18]$, but the objective of this work is to gather the experimental protocols used by the few groups currently working in this field, the results they obtained, and the limitations of this method.

\section{ATTENUATED TOTAL REFLECTION SPECTROSCOPY}

\section{Principles}

Internal reflection spectroscopy is based on the existence of an evanescent wave in a medium of lower index of refraction in contact with an optically denser medium in which a light is introduced [14]. This evanescent field decays exponentially in the rarer medium according to equation (1), so that the light probes only the first micrometers of this medium $[16,19]:$

$$
E=E_{0} \exp \left[-\frac{2 \pi}{\lambda_{1}}\left(\sin ^{2} \theta-n_{21}^{2}\right)^{1 / 2} Z\right]=E_{0} \exp (-\gamma Z)
$$

where $\lambda_{1}=\lambda / \mathrm{n}_{1}$ is the wavelength of the radiation in the denser medium, $\lambda$ is the wavelength in free space, $\theta$ is the angle of incidence with respect to the normal, $\mathrm{n}_{21}=\mathrm{n}_{2} / \mathrm{n}_{1}$, where $n_{1}$ and $n_{2}$ are respectively, the refractive index of the optically denser and rarer medium, and $\mathrm{Z}$ is the distance from the surface [14] (see Fig. 1).

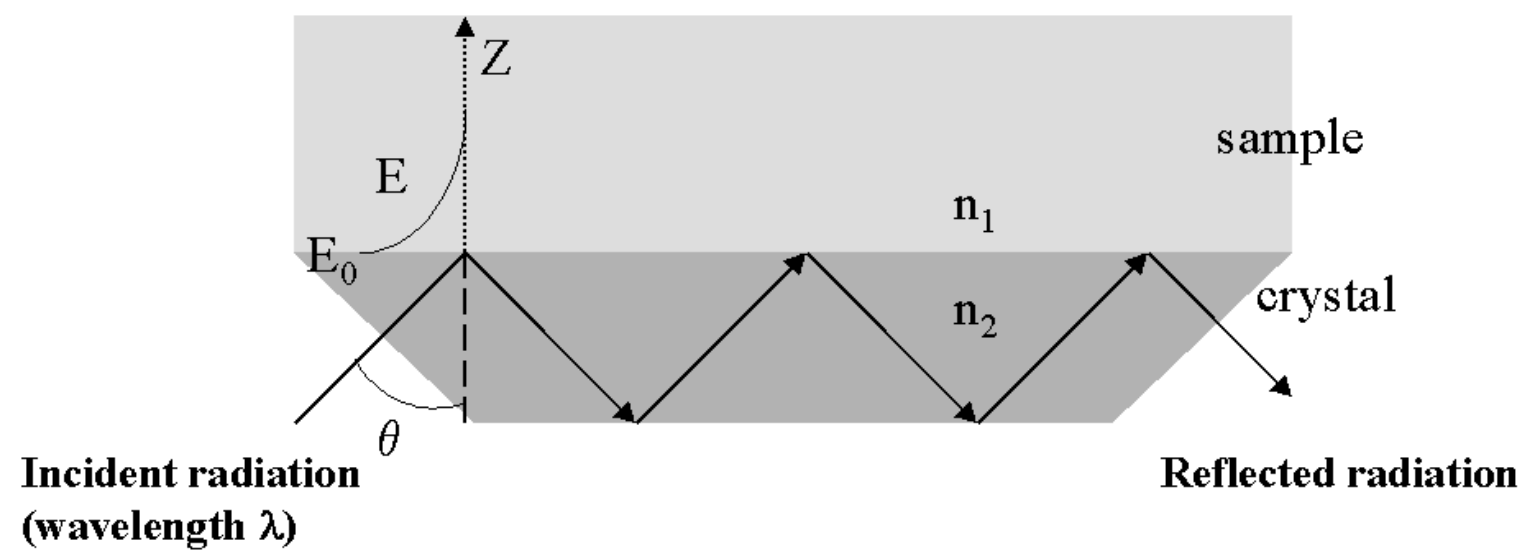


Fig. 1. Schematic diagram of a horizontal sampling accessory illustrating the parameters of significance to evanescent wave. Adapted from Hind et al. [17].

If the sample absorbs radiation, the reflected wave becomes attenuated, and its reflectance is expressed as follows for $\mathrm{N}$ reflections:

$$
\mathrm{R}^{\mathrm{N}}=\left(1-\alpha \mathrm{d}_{\mathrm{e}}\right)^{\mathrm{N}}
$$

where $d_{e}$ is the effective path length and $\alpha$ the absorptivity of the layer. $d_{e}$ is defined as the thickness required to obtain the same absorption in transmission measurement as that obtained in reflectance experiment.

From equation (1), different parameters can be defined to characterize the depth of penetration. The earlier definition was the depth at which electric field amplitude falls to half its value at the surface $(Z=0.69 / \gamma)$, but the current definition of the depth of penetration $\left(d_{p}\right)$ is the value of $Z=1 / \gamma$, therefore a decay of the electric field of $63 \%$. Moreover, this value is lower than the actual depth sampled $\left(\mathrm{d}_{\mathrm{s}}\right)$, which was about three times $\mathrm{d}_{\mathrm{p}}$ (decay of the electric field of $95 \%$ ) $[14,20]$. Equation (1) can be used to obtain the value of $d_{p}$ in a homogeneous solution, but there is a great concern for the determination of depth of penetration through oxy-hydroxide films.

Indeed, when studying the ions adsorbed on layers of particles deposited on ATR crystals, it is interesting to know if the whole layer is probed. Hug and Sulzberger [16] have applied the formula (1) with a volume-weighted average of the refractive index of the particle material and the aqueous solution:

$$
\mathrm{n}_{2}=\mathrm{F}_{\mathrm{v}} \times \mathrm{n}_{\mathrm{par}}+\left(1-\mathrm{F}_{\mathrm{v}}\right) \times \mathrm{n}_{\mathrm{water}}
$$

where $F_{v}$ is the volume fraction of solid and $n_{p a r}$ the refractive index of the pure solid. This water content is required to explain the possibility of using ATR spectroscopy on layers of solids whose refractive indexes (RI) are greater than those of $\mathrm{ZnSe}(2.4)$, as hematite (RI 
$3[21]$ ) or anatase (RI of 2.6 [22]). The depth of penetration, $d_{p}$, is expressed as (from the review by Coates [19]):

$$
\mathrm{d}_{\mathrm{p}}=\frac{\lambda_{1}}{2 \pi}\left(\sin ^{2} \theta-\mathrm{n}_{21}^{2}\right)^{-1 / 2}
$$

or, with $v$, the frequency in wavenumbers $\left(\mathrm{cm}^{-1}\right)$ :

$$
\mathrm{d}_{\mathrm{p}}=\frac{10000}{2 \pi v \mathrm{n}_{1}}\left(\sin ^{2} \theta-\mathrm{n}_{21}^{2}\right)^{-1 / 2}
$$

From the mass of $\mathrm{TiO}_{2}$ deposited on the crystal and its thickness $(1.7 \pm 0.3 \mu \mathrm{m})$ measured with an atomic force microscope, a volume fraction between 0.30 and 0.40 was calculated, leading to $d_{p}$ values between 2 and $2.6 \mu \mathrm{m}$ (Table 1). The actual depth sampled would be $c a .6 \mu \mathrm{m}\left(\mathrm{d}_{\mathrm{S}}=3 \times \mathrm{d}_{\mathrm{p}}\right)$, larger than the layer thickness. It is noteworthy that the refractive index of the particles layer is larger than those of bulk water $\left(\mathrm{n}_{\text {water }}=1.34\right)$, leading to a deeper penetration in the particle layer. In a work on hematite properties, Hug [12] compares the penetration depth in $\mathrm{H}_{2} \mathrm{O}\left(1.39 \mu \mathrm{m}\right.$ at $\left.1100 \mathrm{~cm}^{-1}\right)$ with the thickness of the particle layer and conclude that the entire $\mathrm{Fe}_{2} \mathrm{O}_{3}$ layer is probed. From the values of $\theta$ and $\mathrm{Fe}_{2} \mathrm{O}_{3}$ density given in this article [12] and the refractive index of hematite $\left(\mathrm{n}_{2} \sim 3\right.$ [21]), the condition of internal reflectance, expressed as $\left(\sin ^{2} \theta-\mathrm{n}_{21}{ }^{2}\right) \geq 0$, leads to an upper limit value for $\mathrm{n}_{2}$ of $2^{-1 / 2} \times \mathrm{n}_{\mathrm{ZnSe}}=1.70$, corresponding to a maximum volume fraction of solid $\left(\mathrm{F}_{\mathrm{v}}\right)$ of 0.22 , despite that the given density of loose particle layer $\left(2 \mathrm{~g} \cdot \mathrm{cm}^{-3}\right)$ leads to a slightly larger value (0.24). The calculation of the penetration depth in the particles layer $d_{p}$ for an angle of incidence close to the limit gives large values, and the penetration of the evanescent wave is always less deep in bulk water than in a loose particles layer, for the usual case of a refractive index of the bulk solid higher than that of water. The value of $3 \times \mathrm{d}_{\mathrm{p}}$ for bulk water, $c a .4 \mu \mathrm{m}$ at $1100 \mathrm{~cm}^{-1}$, may be considered as the upper value for the thickness of a deposited film, to ensure the sampling of the whole layer. This value is lower than the usual thickness of layers, and the calculation of the $d_{p}$ in the particles layer would be needed only if a thicker layer is 
deposited, all the more so that the presence of particles increases the penetration depth (table $1)$.

Table 1. Penetration depth at $1100 \mathrm{~cm}^{-1}\left(\mathrm{~d}_{\mathrm{p}}\right)$ in a layer of $\mathrm{TiO}_{2}$, and parameters used in its calculation: volume fraction of solid $\left(\mathrm{F}_{\mathrm{v}}\right)$, layer thickness $(\mathrm{d})$ and refractive index of the layer $\left(\mathrm{n}_{2}\right)$ (from Hug and Sulzberger [16], the refractive index was erroneously named $\mathrm{n}_{1}$ in the original table).

\begin{tabular}{cccc}
\hline $\mathrm{d}(\mu \mathrm{m})$ & $\mathrm{F}_{\mathrm{v}}$ & $\mathrm{n}_{2}$ & $\mathrm{~d}_{\mathrm{p}}(\mu \mathrm{m})$ \\
\hline 2.00 & 0.30 & 1.53 & 2.01 \\
1.72 & 0.35 & 1.57 & 2.25 \\
1.50 & 0.40 & 1.60 & 2.61 \\
\hline
\end{tabular}

\section{Crystals}

There is a wide choice of crystals for ATR spectroscopy, explained by the diversity of the fields where this technique is used (biology, semiconductor technology, earth sciences,...). For the application of in situ investigation of solid/solution interfaces, two main characteristics are required to choose a material: its resistance to solutions with mild acid-base characteristics $(\mathrm{pH} 4-10)$ and a low transmission threshold since the lowest vibrations of sorbed ions (Se-O, As-O) takes place around 750 $\mathrm{cm}^{-1}$. In most of the published studies [4,11,12,23-32], ZnSe was used, the other materials were AMTIR (Amorphous Material which Transmits Infrared Radiation) [33,34],Ge [12,27] and diamond [35]. A summary of the properties of these materials can be seen in Table 2 . Other materials (KRS-5, Si,...) have major drawbacks such as solubility in water or small transmission range. 
Table 2. Properties of materials used for ATR crystals [17,19]

\begin{tabular}{|c|c|c|c|c|}
\hline Material & $\begin{array}{l}\text { Refractive } \\
\text { Index }\end{array}$ & Chemical resistance & $\begin{array}{l}\text { Mechanical } \\
\text { resistance }\end{array}$ & $\begin{array}{c}\text { Transmission } \\
\text { threshold }\left(\mathrm{cm}^{-1}\right)\end{array}$ \\
\hline $\mathrm{ZnSe}$ & 2.4 & $\begin{array}{l}\text { etched by diluted acids and bases, } \\
\text { eroded by zinc complexants }\end{array}$ & $\begin{array}{l}\text { easily } \\
\text { cracked }\end{array}$ & 650 \\
\hline AMTIR & 2.5 & $\begin{array}{l}\text { attacked by bases and oxidizing } \\
\text { acids }\end{array}$ & very brittle & 750 \\
\hline $\mathrm{Ge}$ & 4.0 & resistant to diluted acids and bases & brittle & 870 \\
\hline Diamond & 2.4 & suitable to $\mathrm{pH} 1$ to 14 & very hard & $<200$ \\
\hline
\end{tabular}

\section{Cells and methods of solid deposition}

Two methods were used to bring particulate matter into contact with the crystal: (1) spreading a concentrated suspension $[4,25,31]$ or a paste $[27,29,33,34,36]$ on the crystal or (2) coating by colloidal particles to form a film stable toward stirring or flowing of the solution in direct contact. $[11,12,16,23-26,28,32]$. For the first method, the equilibrium of the system solid/solution is reached by a classical batch experiment, then the suspensions are centrificated to obtain a suspension with a high mass/volume ratio. Samples as suspensions of $100-1000 \mathrm{~g} / \mathrm{L}$ of oxides, or as a paste covering the entire crystal spread by means of a plastic spatula [33], are analyzed. Hug and Sulzberger [16] have pointed out several factors which complicate quantitative measurements by this method, as the dependence of the concentration of particles in the proximity of the ATR element on $\mathrm{pH}$ and surface coverage with adsorbate. This point was detailed by Tickanen et al. [20] who propose a methodology for determining the concentration of suspended goethite particles sampled by the evanescent wave from a cylindrical internal reflection (CIR) element. On the other hand, the paste method allow easily to determine the surface coverage, and the spectroscopic results can straightforwardly used in surface complexation modeling. The drawback of the layer method is a possible effect of the 
structure of the colloid deposit on the surface reactivity and accessibility, hindering the comparison with results obtained on the well-dispersed colloidal suspension.

In order to increase the surface probed by the evanescent light and to avoid the problem of changing dispersitivity of particles in suspension, Hug and Sulzberger $[12,16]$ have performed the coating of the crystal with a stable layer of colloidal oxy-hydroxides particles. This method, modified by Peak et al. [11], begins by the synthesis of solids with high specific surface areas in suspension. Then, Hug [12] has prepared hematite layers as follows: " $20 \mu \mathrm{L}$ $\mathrm{Fe}_{2} \mathrm{O}_{3}$ suspension (containing ca. $3.2 \mathrm{mg} \mathrm{Fe} \mathrm{O}_{3}$ ) mixed with $20 \mu \mathrm{L}$ ethanol was distributed over the ATR crystal. After drying, the layers were rinsed with $\mathrm{H}_{2} \mathrm{O}$ until no more $\mathrm{Fe}_{2} \mathrm{O}_{3}$ detached". For goethite film, Peak et al. [11] have described their method: " $500 \mu \mathrm{L}$ of $0.01 \mathrm{M}$ $\mathrm{NaCl}$ adjusted to $\mathrm{pH} 4.5$ was pipetted onto the crystal, forming a large droplet. Then, $10 \mu \mathrm{L}$ of a 250 g.L $\mathrm{L}^{-1}$ goethite suspension was placed into the center of the droplet with a pipette. The suspension was then mixed and spread evenly across the surface of the crystal using the pipette tip and allow to dry. Once the deposit was dry, it was rinsed by holding it at an angle, placing a large drop of $0.01 \mathrm{M} \mathrm{NaCl}$ onto one edge, and allowing the droplet to slowly move across the deposit. At the end, the excess electrolyte was absorbed with a KimWipe". Hug [12] has estimated that $10-20 \%$ of initially deposited solid remained after rinsing, but Peak et al. [11] have weighed the crystal after deposition and found that all the goethite added forms a deposit. The difference between rinsing techniques may explain these opposite values.

No study on the characteristics of the film deposit on the ATR crystal was published, but films of colloids deposited in the same manner into other smooth supports were characterized by Degenhardt and McQuillan [24] who have studied a film of chromium hydroxide sol evaporated onto glass by SEM. It consists of a patchy multilayer of particles whose average diameter was $430 \mathrm{~nm}$, and was about $2.5 \mu \mathrm{m}$ thick. Connor et al. [37] have observed by SEM layers of $\mathrm{ZrO}_{2}, \mathrm{TiO}_{2}$ and $\mathrm{Al}_{2} \mathrm{O}_{3}$ evaporated onto an aluminum disc. The film consists in flakes 
of solid, whose thickness is less than $1 \mu \mathrm{m}$, separated by vacuum-formed cracks. Thus, before placing under vacuum, this film should continuously coated the support. Thickness of the films was characterized or calculated for several solids as hematite (0.2-0.4 $\mu \mathrm{m}$ [12]), $\mathrm{TiO}_{2}$ (1.7 $\pm 0.3 \mu \mathrm{m}[16]$ or $1 \mu \mathrm{m}[26,37]), \mathrm{ZrO}_{2}(1 \mu \mathrm{m}[37]), \mathrm{Al}_{2} \mathrm{O}_{3}(1 \mu \mathrm{m}$ [37]), $\mathrm{Cr}(\mathrm{III})$ oxyhydroxide $(2.5 \mu \mathrm{m}[24])$ or silica $(1 \mu \mathrm{m}$ [26]). In all cited cases, the entire layer should be probed by the evanescent wave (see principles part).

Other methods have been developed to obtain an oxide layer on an ATR substrate in relation with optical sensors of molecules in aqueous media $[38,39]$. Thus, sol-gel precursors of $\mathrm{SiO}_{2}$ was found suitable producing thin $(1.7 \mu \mathrm{m})$ homogeneous films on $\mathrm{ZnSe}$ [38]. Ninness at al. [39] have presented a technique using a binder (polyethylene) to anchor colloidal silica paticles on $\mathrm{ZnSe}$. The coating layer (about $5 \mu \mathrm{m}$ in thickness) consisted in islands of $20 \mu \mathrm{m}$ in size, separated by $5 \mu \mathrm{m}$ cracks. Gas-phase reactions with silanes were used to evaluate the accessibility of the surface of silica, indicating that most of the hydroyl groups are reactive.

Once the modified ATR crystal was prepared, it was generally placed into a flow cell (excepted in studies by Wijnja and Shulthess [25] and Gong [26] where static cells were used). The diagram of the experimental apparatus designed to study the interactions between the film of metal oxy-hydroxide and solution species (including protons) is shown in Fig. 2. The composition of the solution which flows onto the ATR crystal are changed by adding concentrated solutions of acid, base or adsorbing species in the reservoir (500 $\mathrm{mL}$ vessel), where the $\mathrm{pH}$ is measured. The flow rate value varied from $1 \mathrm{~mL} \cdot \mathrm{min}^{-1}$ to $7 \mathrm{~mL} \cdot \mathrm{min}^{-1}$ $[16,23,24,28,30,32]$. 


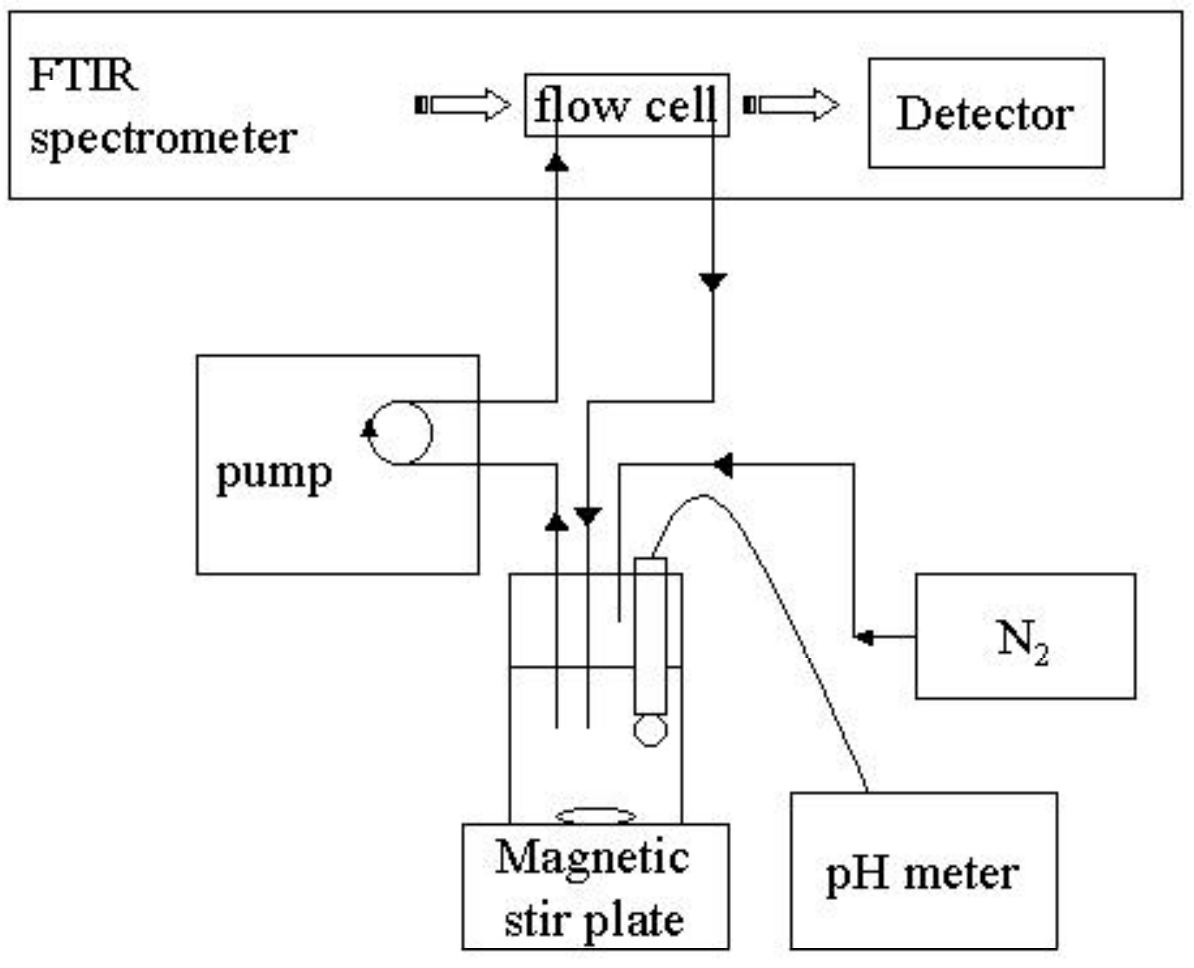

Fig. 2. Experimental apparatus used for $\mathrm{pH}$ envelopes and adsorption isotherms.

Adapted from Peak et al. [11]

A cell with a horizontal trough configuration was generally used, equipped with a crystal with coated upper face. Considering the adhesion strength of solid particles, a crystal with both sides coated may be used surrounded by solution, however, the author is unaware of any reported interfacial investigation using such a cell. Its advantage would be an increased sensitivity (almost twice) compared to single-coated crystals despite of some experimental complications.

Solution 
The ionic strength of solutions is usually kept constant in sorption experiments, since it has an impact on the activity coefficients of aqueous species, but yet more on the surface charge of the solid particles. Ions considered to be inert, or non-sorbing on solid surfaces, are used as background electrolyte: $\mathrm{Na}^{+}, \mathrm{K}^{+}, \mathrm{Cl}^{-}, \mathrm{NO}_{3}{ }^{-}$and $\mathrm{ClO}_{4}{ }^{-}$[40]. Due to the absence of absorption in mid-IR range, $\mathrm{Cl}^{-}$was used in most of the ATR experiments $[4,11,16,23,25$, 27,29-31,33]. In spite of the bands of $\mathrm{NO}_{3}^{-}\left(\sim 1300 \mathrm{~cm}^{-1}\right)$ and $\mathrm{ClO}_{4}^{-}\left(\sim 1100 \mathrm{~cm}^{-1}\right)$, sodium salts of these ions were used in studies involving metal ions (respectively $\mathrm{U}(\mathrm{VI})$ [36] and $\mathrm{Pb}(\mathrm{II})$ [34]) to avoid the formation of chloride complexes. However, the inert electrolyte must be carefully chosen in function of the solid since specific adsorption of $\mathrm{Cl}^{-}$was mentioned on $\gamma$ alumina [41] and $\mathrm{Cu}_{2} \mathrm{O}$ [42]. The iep (isoelectric point determined by eletrophoretic measurements) and pzse (point of zero salt effect: common intersection point of the acid-base titrations curves at different ionic strengths) of goethite [43], haematite [44] or anatase [45] did not vary systematically as a function of the chloride concentration what is an element in favor of a non-specific adsorption, although Rietra et al. [43] have shown that chloride was more able to screen the positive charge of goethite than nitrate or perchlorate, leading to a higher amount of sorbed protons and decreasing the sulfate uptake. A stronger effect of chloride on proton adsorption has been found for $\mathrm{RuO}_{2}$ [46]. Bromide and iodide species seems to have less affinity for surface sites than chloride, on alumina $[41,47]$ and anatase [45]. $\mathrm{KBr}$ was used $[26,48]$ in the study of phosphate sorption on titania by ATR. In spite of the decrease of their reactivity, bromide and iodide have been scarcely used in sorption experiments as background electrolyte, and most of the published studies were carried out with $\mathrm{Cl}^{-}, \mathrm{NO}_{3}{ }^{-}$and $\mathrm{ClO}_{4}{ }^{-}$. The comparison of ATR results with previous studies is therefore easier for $\mathrm{Cl}^{-}$background electrolyte when studying the surface reactivity of iron oxyhydroxides. 
Concentration of the dissolved species in equilibrium with the sorbed fraction on solid particles is another characteristics of the solution. The numerous applications of solid/solution researches in the field of environment pollution deal with concentrations spanning several orders of magnitude, from traces of radioactive ions to values greater than $0.01 \mathrm{M}$ near dissolving fertilizer particles [49] (phosphate), or in acid mines drainage water [50] (sulfate). A hint for relevant concentrations range for environmental studies may be found in the limit concentration of pollutants as defined by the European directive on the quality of water [51]. For example, maximum concentrations in water intended for human consumption are $10 \mathrm{ppb}$ for As and $\mathrm{Se}(\sim 0.13 \mu \mathrm{M})$, and $50 \mathrm{ppm}$ for $\mathrm{NO}_{3}{ }^{-}(0.81 \mathrm{mM})$ [51]. The sensitivity of ATR-IR, as other surface analysis methods, depends on the surface coverage with adsorbate. The experimental apparatus (Fig. 2) used for adsorption isotherms on particles layer leads to a high volume/mass ratio, thus a high coverage can be obtained with low dissolved concentrations. Moreover, ATR-IR sensivity to sorbed oxoions is very dependent on the contact between the particulate matter and the crystal. Thus, crystals coated according to Hug's method $[12,16]$ have allowed studies with sulfate or arsenate concentrations lower than $10 \mu \mathrm{M}[11,12,16,28]$, whereas analysis of slurry have been performed with adsorbate concentrations between $1 \mathrm{mM}$ and $0.5 \mathrm{M}[4,29]$. The sorption process allows to increase the signal of the ions by a huge factor, in comparison with dissolved species, and this characteristics has been used to develop sensors [38] to monitor organophosphates in natural waters down to sub-ppm concentration range.

Other parameters play a role in the sensitivity of the analysis, as the number of internal reflections, the specific area of the solid or the absorptivity of the detected ion. .The $\mathrm{pH}$ values in the published works were in the range $3-9$ (until 2-11 in a few works $[22,24]$ ), correlated to the $\mathrm{ZnSe}$ chemical resistance. This range corresponds to the usual $\mathrm{pH}$ values of sorption 
studies, although the $\mathrm{ZnSe}$ resistance may limit the study of the surface reactivity at $\mathrm{pH}$ values higher than the iep of iron and aluminum oxy-hydroxides $(\sim 8-10)$.

\section{Solids}

The majority of studies have involved high surface area solids, to increase the likelihood of obtaining good contact and to allow the probing of a high amount of sorbed species [17]. It is the case of goethite, whose specific surface area varies between 50 and $100 \mathrm{~m}^{2} / \mathrm{g}$ as a function of the parameters of its synthesis, which has been the subject of a number of studies $[4,11,20,23,25,30,31,33,34,52,53]$. Colloidal hematite (particle size 10-25 nm) and titania (particle size 20-30 nm), whose geometrical specific surface areas are higher than $50 \mathrm{~m}^{2} / \mathrm{g}$, are the first solids that have been used to coat ATR crystals $[12,16]$. Amorphous metallic oxyhydroxides are known to have even higher specific surface areas, as the compounds of iron (ca. $\left.250 \mathrm{~m}^{2} / \mathrm{g}[4,27,29,31]\right)$ or aluminum $\left(130 \mathrm{~m}^{2} / \mathrm{g}[29,31]\right)$.

\section{RESULTS}

Due to the principle of IR spectroscopy, only polyatomic ions can be probed by this method, by the $\mathrm{M}-\mathrm{O}$ vibrations (where $\mathrm{M}$ represents $\mathrm{S}, \mathrm{C}, \ldots$ ). Thus, studies can be carried out on a limited number of inorganic oxoanions whose free ion is detected between $1500 \mathrm{~cm}^{-1}$ (carbonate) and ca. $750 \mathrm{~cm}^{-1}$ (selenite) (see Table 3). The transmission threshold of the crystal material determines the lowest wavenumbers which can be measured, so the use of materials with high thresholds (Ge for example) prevents from studying "heavy" oxoanions, since the stretching vibrations reach low wavenumbers for heavy element (as illustrated by the 
comparison between $\mathrm{SO}_{4}{ }^{2-}$ and $\mathrm{SeO}_{4}{ }^{2-}$ in Table 3). The strong absorption of $\mathrm{H}_{2} \mathrm{O}$ below 800$850 \mathrm{~cm}^{-1}$ limit studies with this solvent, but this limit can be decrease by ca. $100 \mathrm{~cm}^{-1}$ in $\mathrm{D}_{2} \mathrm{O}$.

Table 3. Positions of peak maxima of dissolved and coordinated anions

\begin{tabular}{|c|c|c|c|c|c|c|c|c|c|c|c|c|c|c|}
\hline \multirow[t]{2}{*}{ species* (reference) } & \multicolumn{14}{|c|}{ Infrared active band positions $\left(\mathrm{cm}^{-1}\right)^{* *}$} \\
\hline & \multicolumn{2}{|c|}{800} & & & \multicolumn{2}{|c|}{1000} & & \multicolumn{3}{|c|}{1200} & \multicolumn{3}{|c|}{1400} \\
\hline $\mathrm{SO}_{4}{ }^{2-}[12,24,25]$ & & & & & & & 1100 & & & & & & & \\
\hline $\mathrm{HSO}_{4}^{-}[12]$ & & & 890 & & & 1050 & & & 1195 & & & & & \\
\hline hematite-sulfate [12] & & & & & 975 & & 1060 & 1130 & & & & & & \\
\hline goethite-sulfate [11] & & & & & 975 & & 1055 & 1135 & & & & & & \\
\hline goethite-sulfate [25] & & & & & 975 & & 1055 & 1130 & & & & & & \\
\hline COH-sulfate [24] & & & & & 980 & & 1060 & 1120 & & & & & & \\
\hline $\mathrm{ClO}_{4}^{-}[24]$ & & & & & & & & 1105 & & & & & & \\
\hline $\mathrm{COH}$-perchlorate [24] & & & & & & & & 1105 & & & & & & \\
\hline $\mathrm{TiO}_{2}$-perchlorate [22] & & & & & & & & 1104 & & & & & & \\
\hline $\mathrm{S}_{2} \mathrm{O}_{3}{ }^{2-}[24]$ & & & & & 995 & & & 1115 & & & & & & \\
\hline COH-thiosulfate [24] & & & & & 995 & & & 1105 & & & & & & \\
\hline $\mathrm{AsO}_{4}{ }^{3-}[28]$ & 790 & & & & & & & & & & & & & \\
\hline $\mathrm{HAsO}_{4}^{2-}[28]$ & & & 860 & & & & & & & & & & & \\
\hline $\mathrm{H}_{2} \mathrm{AsO}_{4}^{-}[28]$ & 740 & & 880 & 910 & & & & & & & & & & \\
\hline HFO-arsenate [28] & & 825 & & & & & & & & & & & & \\
\hline $\mathrm{B}(\mathrm{OH})_{4}^{-}[29]$ & & & & & 955 & & & & 1170 & & & & & \\
\hline $\mathrm{B}(\mathrm{OH})_{3}^{0}[29]$ & & & & & & & & & 1150 & & & & 1410 & \\
\hline HAO-borate [29] & - & - & - & - & - & & & & & & 1280 & & 1420 & \\
\hline HFO-borate [29] & & & & & 985 & & & & & 1255 & 1295 & & 1400 & \\
\hline $\mathrm{PO}_{4}^{3-}[27,52]$ & & & & & & 1005 & & & & & & & & \\
\hline $\mathrm{HPO}_{4}^{2-}[27,52]$ & & 850 & 890 & & 990 & & 1075 & & & & & & & \\
\hline $\mathrm{H}_{2} \mathrm{PO}_{4}^{-}[27,52]$ & & 875 & & 940 & & & 1075 & & 1155 & & & & & \\
\hline $\mathrm{H}_{3} \mathrm{PO}_{4}[27,52]$ & & & 890 & & & 1005 & & & 1175 & 1250 & & & & \\
\hline goethite-phosphate [52] & - & - & - & - & & 1005 & 1045 & 1100 & 1120 & & & & & \\
\hline $\mathrm{TiO}_{2}$-phosphate [32] & & & & & 985 & 1030 & & 1100 & & & & & & \\
\hline $\mathrm{TiO}_{2}$-phosphate [26] & & & & 915 & 980 & 1010 & 1055 & 1115 & & & & & & \\
\hline FH-phosphate [27] & & & & 950 & & 1020 & 1090 & & & & & & & \\
\hline $\mathrm{CO}_{3}^{2-}[31]$ & & & 885 & & & & 1065 & & & & & 1385 & & \\
\hline $\mathrm{HCO}_{3}^{-}[31]$ & & 845 & & & & 1010 & & & & & 1310 & 1360 & & \\
\hline HAO-carbonate [31] & - & - & - & - & - & 1030 & & & & & & & 1420 & 1490 \\
\hline$\gamma$ alumina-carbonate $[54]$ & - & - & - & - & & & & & & & & 1390 & & 1510 \\
\hline HFO-carbonate [31] & & & & & & & 1070 & & & & 1335 & & 1410 & \\
\hline hematite-carbonate [36] & & & & & & & & & & & 1350 & & & 1500 \\
\hline goethite-carbonate [33] & - & - & - & - & & & & & & & 1335 & & & 1490 \\
\hline $\mathrm{SeO}_{4}^{2-}[4]$ & & & 870 & & & & & & & & & & & \\
\hline $\mathrm{SeO}_{3}^{2-}[4]$ & 730 & 825 & 850 & & & & & & & & & & & \\
\hline goethite-selenate [55] & & 820 & 850 & 880 & & & & & & & & & & \\
\hline HFO-selenate [4] & & & & 885 & 895 & & & & & & & & & \\
\hline HFO-selenite [4] & 750 & 845 & & & & & & & & & & & & \\
\hline $\mathrm{NO}_{3}^{-}[54]$ & & & & & & & & & & & 1350 & & & \\
\hline$\gamma$ alumina-nitrate [54] & - & - & - & - & & & & & & & 1350 & & & \\
\hline
\end{tabular}


* abreviations of the names of solid phases: $\mathrm{COH}=\mathrm{Cr}(\mathrm{III})$ oxide hydroxide, $\mathrm{HFO}=$ amorphous ferric oxide, $\mathrm{HAO}=$ amorphous aluminum oxide, $\mathrm{FH}=$ ferrihydrite; $* *$ range where absorption bands of the solid phases prevent the detection of sorbed species is dotted

Moreover, the symmetry of these ions is lowered when they sorbed onto minerals surface via an inner-sphere complex, leading to a peak split of ca. $150 \mathrm{~cm}^{-1}$ for carbonate [33] and sulfate [12] for example. This effect must be taken into account when planning to study oxoanions whose vibration of free species is close to the transmission threshold of the ATR crystal or of the solvent. On the other hand, the outer-sphere sorption, as illustrated by perchlorate ion, has a weak impact on the ion symmetry and no change may be expected between vibration wavenumbers of free and sorbed ion.

\section{Sulfate}

The adsorption mechanism of sulfate ions onto oxides was not been resolved during years.

The main issue was to determine if sulfate is sorbed as an inner-sphere (IS) or an outer-sphere (OS) complex. From macroscopic experiments, it was observed that ionic strength has a large effect on the fraction of sulfate that is adsorbed onto goethite [56], what have led Perrson and Lövgren [56] to model this sorption by two OS complexes ( $\equiv \mathrm{FeOH}_{2}{ }^{+} \mathrm{SO}_{4}{ }^{2-}$ and $\equiv \mathrm{FeOH}_{2}{ }^{+} \mathrm{HSO}_{4}{ }^{-}$). However, sulfate adsorption shifts the point of zero charge of goethite to higher values, which is characteristic of an IS complex. The use of in situ ATR-FTIR spectroscopy have brought new elements to understand this problem. The infrared spectra of sulfate species relates to the symmetry of the complex, as shown in table 4. Sulfate in solution belongs to the point group $\mathrm{T}_{\mathrm{d}}$, and only one peak at ca. $1100 \mathrm{~cm}^{-1}$ is observed, corresponding 
to the triply degenerate asymmetric stretching vibration $\left(v_{3}\right)$. Complexation of the sulfate ion lowers its symmetry, leading to a split of the $v_{3}$ in two (for $\mathrm{C}_{3 \mathrm{v}}$ point group) or three $\left(\mathrm{C}_{2 \mathrm{v}}\right.$ or $C_{1}$ ) peaks while the symmetric stretching $v_{1}$ becomes active around $950 \mathrm{~cm}^{-1}$. As shown by the bands of sulfate/cobalt complexes, the characterization of the $v_{3}$ split may determine the structure of the surface complex, i.e. monodentate or bidentate.

Table 4. Positions of peak maxima of dissolved sulfate and Co(III) sulfato complexes

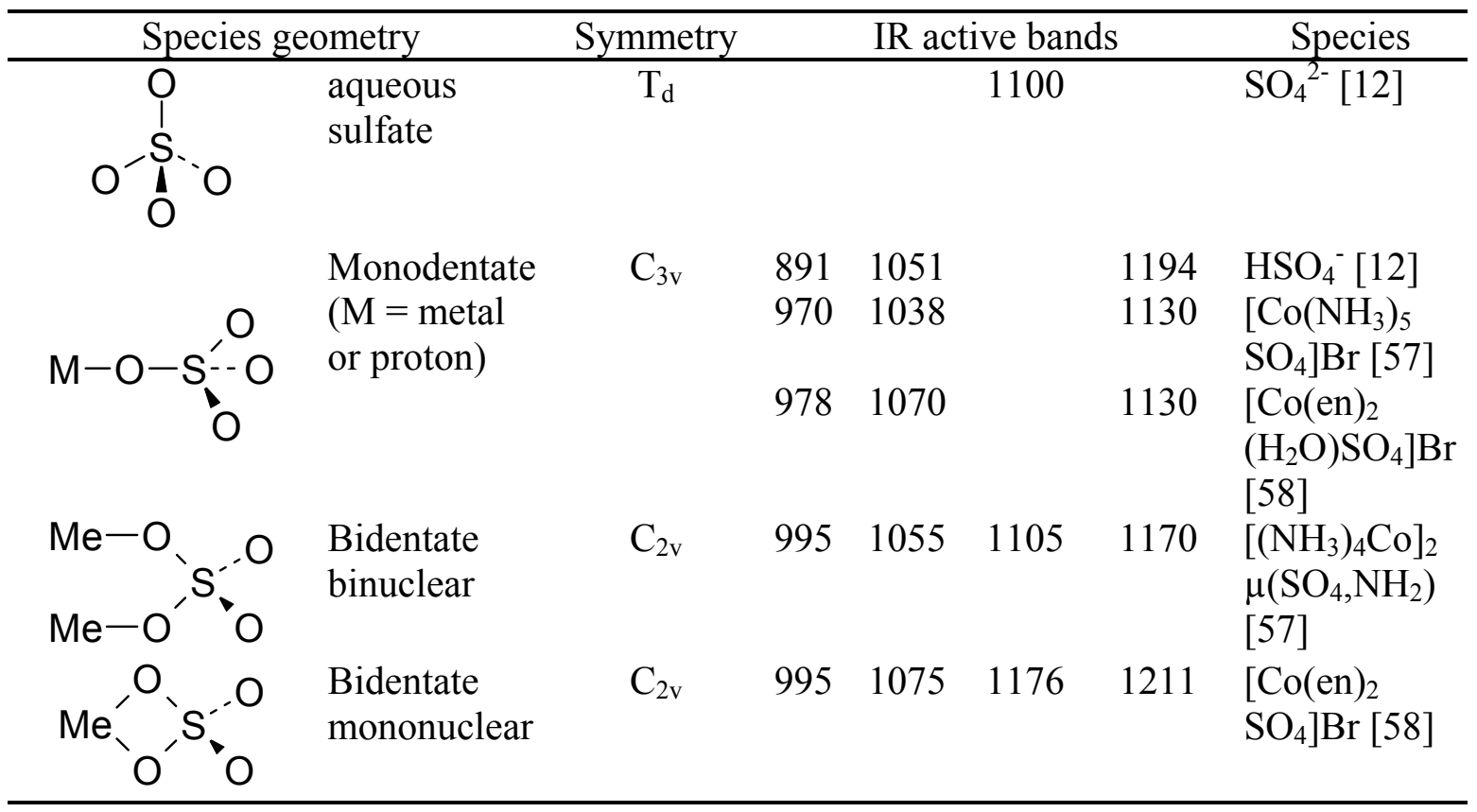

Infrared spectroscopies have led to opposite results too, since a bidentate binuclear complex was identified by FTIR [59], whereas an OS complex was shown by DRIFT [56]. It is noteworthy that the analyzed samples were potentially altered by drying or dilution in a salt that may modify the structure of the original surface complex. The conclusion of ATR-IR experiments is that sulfate adsorption on goethite [11] occurs via both OS and IS complexation. On amorphous chromium (III) oxy-hydroxide [24], the signal of sorbed sulfate was interpreted as an OS complex due to the lack of a clear split of the absorption band. 
However, the asymmetry of the peak for the lowest $\mathrm{pH}$ may suggest the contribution of an IS complex, which would have a weak contribution to the total signal. On hematite [12], the sorption takes place mainly by IS complexation, with a contribution of an OS complex for $\mathrm{pH}$ $5-7$. Experiments on the adsorption of sulfate have been also carried out on $\mathrm{TiO}_{2}$ (anatase) [16]. Despite the large contribution of the sulfate species present in the solution, what complicates the spectra, the absorption signal reveals two shoulders on either side of the main peak, ascribed to the split due to an IS complex. In conclusion, the results obtained by this method has pointed out the possibility for an ion to sorb via both OS and IS complexation reaction. This possibility, even if it is not surprising, have been rarely suggested due to the lack of other experimental methods to highlight this behavior. ATR-FTIR spectroscopy allows the simultaneous detection of the both kinds of complexes, but the decomposition of the signal remains tricky. Thus, Hug and Sulzberger [16] have found that the signal of sulfate adsorbed onto $\mathrm{TiO}_{2}$ may be reconstructed from three peaks corresponding to the contribution of sulfate species present in the probed solution (pointed out at $1105 \mathrm{~cm}^{-1}$ ), and two kinds of sorbed sulfate distinguished by different Langmuir constants. The chemical nature of these two sorbed species is unclear, and the main reason of this interpretation is the good fit obtained on the adsorption isotherm. The spectral curve fitting of sulfate adsorbed onto hematite [12] was carried out by using three peaks (Fig. 3), according to an IS complex with a $\mathrm{C}_{3 \mathrm{v}}$ symmetry, two Lorentzians for the split $v_{3}\left(1055\right.$ and $\left.1130 \mathrm{~cm}^{-1}\right)$ and a Lorentzian for $v_{1}$ $\left(975 \mathrm{~cm}^{-1}\right)$. Spectra recorded on sulfate-treated goethite $[11,60]$ were very similar to those obtained on hematite [12] but two Gaussian peaks attributed to an OS complex (degenerated $v_{3}$ at $1108 \mathrm{~cm}^{-1}$ and $v_{1}$ at $975 \mathrm{~cm}^{-1}$ ) were included along the Gaussian peaks coming from an IS complex with a $C_{2 v}\left(C_{1}\right)$ symmetry $\left(v_{3}\right.$ at 1170,1133 and $1055 \mathrm{~cm}^{-1}$, and $v_{1}$ at $922 \mathrm{~cm}^{-1}$ ) (Fig. 4). 


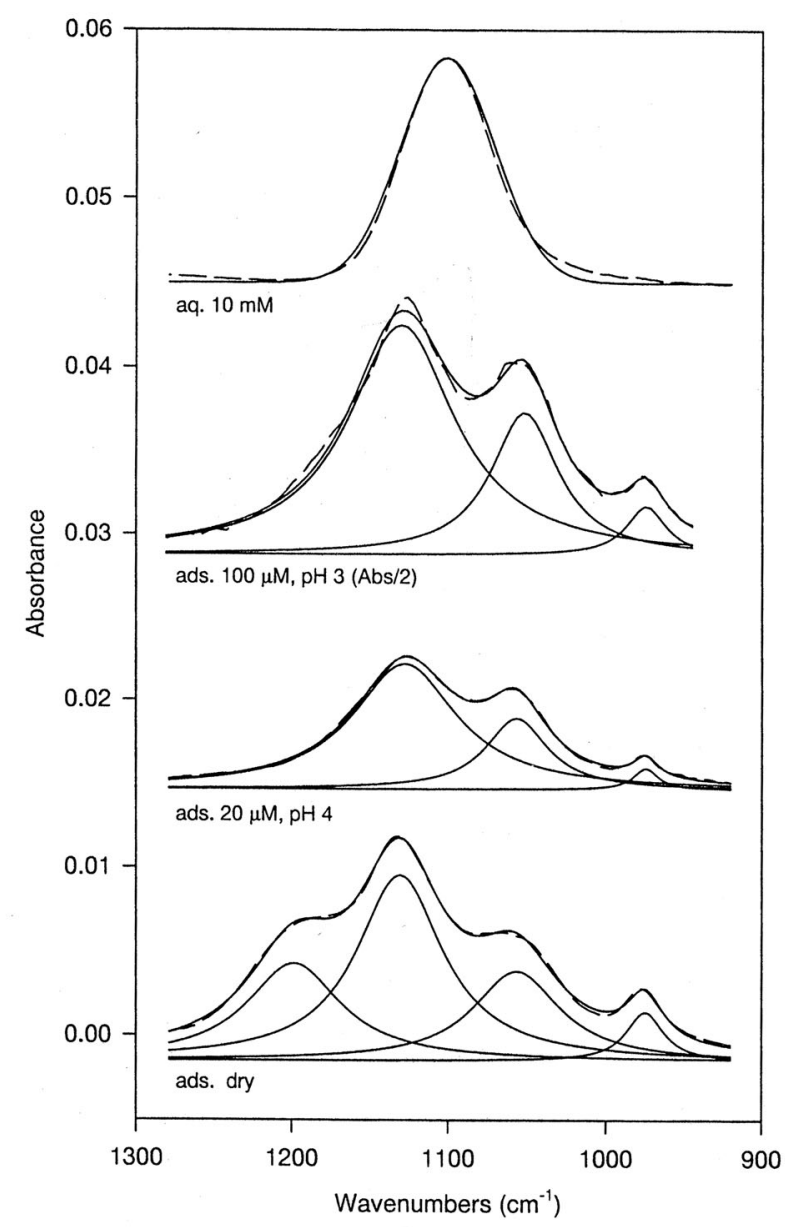

Fig. 3. ATR-FTIR spectra of sulfate adsorbed on hematite and curve fitting. The spectra are offset vertically for clarity. aq. refers to aqueous and ads. to adsorbed sulfate, followed by the aqueous concentrations. Dashed lines are the experimental spectra; solid lines are the fits (reprinted from J. Colloid Interface Sci. 188, S.H. Hug, In situ Fourier transform infrared measurements of sulfate adsorption on hematite in aqueous solutions, pp 415-422, copyright 1997, with permission from Elsevier [12]). 

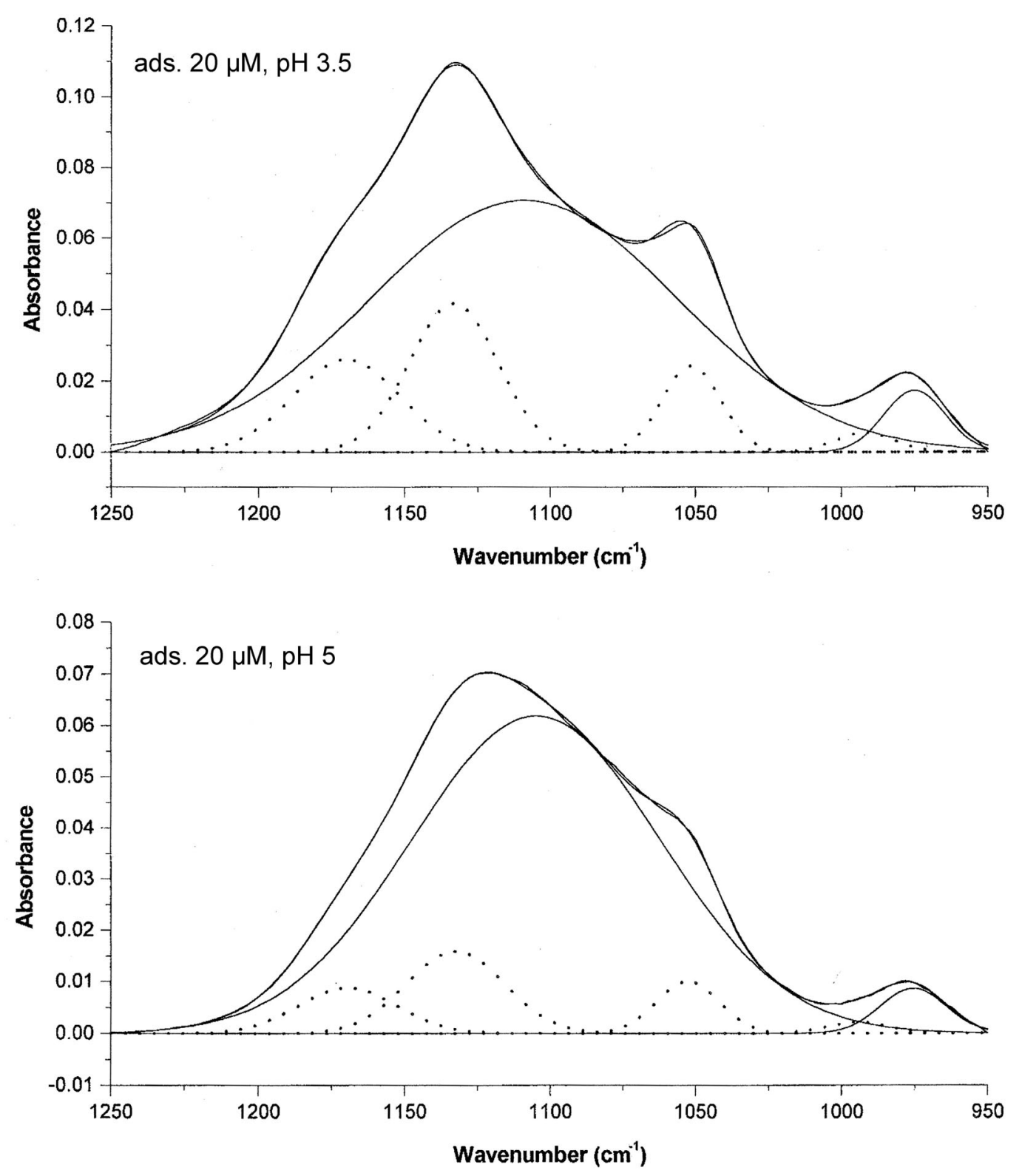

Fig. 4. ATR-FTIR spectra of sulfate adsorbed on goethite and spectral curve fitting. ads. refers to adsorbed sulfate, followed by the aqueous concentrations. The dotted lines denote the peaks arising from an inner-sphere complex (reprinted from J. Colloid Interface Sci. 218, D. Peak, R.G. Ford R.G. and D.L. Sparks, An in-situ FTIR-ATR investigation of sulfate bonding mechanisms on goethite, pp289-299, copyright 1999, with permission from Elsevier [11]). 
Given the similarity between the spectra of sulfate adsorbed onto hematite and goethite, the difference of the conclusions obtained after the decomposition is striking.

\section{Carbonate}

Sorption of carbonate ions on aluminum and iron oxides was found to be relatively weak, since it is strongly influenced by ionic strength and type of electrolyte anion $[33,54]$. However, its effect on the electrophoretic mobility is known [31] and resulting in the iep drop observed on oxides contaminated by carbonate impurity. The free $\mathrm{CO}_{3}{ }^{2-}$ ion has a $\mathrm{D}_{3 \mathrm{~h}}$ symmetry (trigonal planar) and its spectrum is dominated by the $v_{3}$ band (asymmetric stretching) at $1385-1390 \mathrm{~cm}^{-1}[31,54]$. Bicarbonate ion $\left(\mathrm{HCO}_{3}{ }^{-}\right)$has a $\mathrm{C}_{2 \mathrm{v}}$ symmetry leading to a strong band at $1360 \mathrm{~cm}^{-1}$ (symmetric stretching of $\mathrm{CO}_{2}[31,54]$ ) with a shoulder around $1300 \mathrm{~cm}^{-1}$ (COH bend [54]). At 1605 and $1668 \mathrm{~cm}^{-1}$, two bands appear, assigned to the asymmetric stretching of $\mathrm{CO}_{2}$ [31]. In aqueous solution, these latter bands can be obscured by the strong $\mathrm{H}_{2} \mathrm{O}$ absorption. ATR-FTIR analyses were performed on samples of hydrous aluminum oxide (HAO) [31], hydrous ferric oxide (HFO) [31], goethite [31,33,34,61], hematite [36] and aged $\gamma$-alumina [54] after sorption of carbonate. The conclusion of these studies are identical for all studied substrates: carbonate ions form a monodentate complex at the surface $[31,33,34,54,61]$. The distinction between outer-sphere complex, monodentate, bidentate and bridging bidentate complexes is based on the degree of splitting of the $v_{3}(\mathrm{CO})$ stretch vibration seen around $1500 \mathrm{~cm}^{-1}$ (named $\Delta v$ below). From the spectra of some Co(III)carbonato complexes, the splitting criterion was described in table 5. 
Table 5. $\Delta v_{\text {CO }}$ splitting for several coordination modes in Co(III) carbonato complexes (adapted from ref. [54])

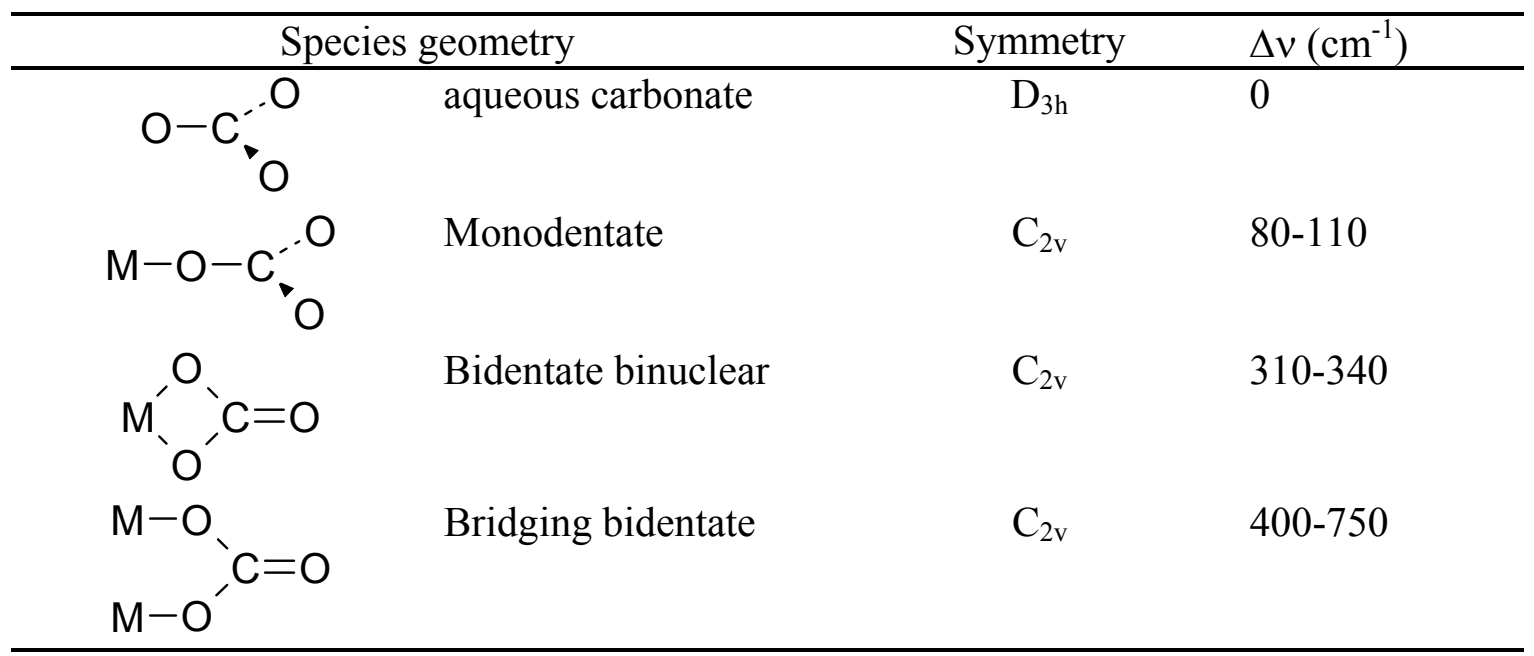

However, $\Delta v$ is correlated with the polarizing power of the cation $\left(\mathrm{z} / \mathrm{r}^{2}\right.$ where $\mathrm{z}$ is the formal charge and $\mathrm{r}$ the ionic radius), what may prevent the comparison between $\Delta v$ measured for Co(III)-carbonato complexes and metal oxy-hydroxides surfaces if this parameter is very different. It is not the case for $\mathrm{Al}(\mathrm{III})$ and $\mathrm{Fe}(\mathrm{III})$ compounds, and the $\Delta v$ is expected to be comparable with the values obtained for the Co(III)-carbonato complexes. Results of determinations of $\Delta v$ are the following: $120 \mathrm{~cm}^{-1}$ for aged $\gamma$-alumina [54] (mainly bayerite $\beta$ $\mathrm{Al}(\mathrm{OH})_{3}$ in surface [62]), $70 \mathrm{~cm}^{-1}$ for HAO [31], $130 \mathrm{~cm}^{-1}$ for HFO [31], 75 [31], 155 [33], $164 \mathrm{~cm}^{-1}$ [34], or $195 \mathrm{~cm}^{-1}$ [61] for goethite, and $150 \mathrm{~cm}^{-1}$ for hematite [36]. All these values are clearly smaller than those measured for bidentate complexes (between 300 and $750 \mathrm{~cm}^{-1}$ ) and may correspond to a monodentate complex. However, the $v_{3}$ band gives no information on the protonation of the complex. Thus, carbonate can be sorbed as $\equiv \mathrm{M}-\mathrm{O}-\mathrm{C}(\mathrm{O}) \mathrm{O}^{-}$or $\equiv \mathrm{M}-\mathrm{O}-$ $\mathrm{C}(\mathrm{O}) \mathrm{OH}$. The main difference between the spectra of carbonate and bicarbonate ions is the presence of two bands around $1600 \mathrm{~cm}^{-1}$ for the latter species. Such bands in the spectrum of sorbed carbonate may reveal the protonation of the surface complex and this criterion was 
used in some studies $[31,54]$ although the absorption of $\mathrm{H}_{2} \mathrm{O}$ in this range complicates this method $[33,54,61]$. However, Wijnja and Schulthess have observed no significant bands around $1600 \mathrm{~cm}^{-1}$ for sorbed carbonate onto a suspension of aged $\gamma$-alumina [54] or goethite [61] in $\mathrm{D}_{2} \mathrm{O}$ and concluded that only a deprotonated surface complex of carbonate is present. A previous macroscopic study [63] has indicated that bicarbonate ions would be sorbed with a proton stoichiometry of $1: 1$, what would be consistent with the following reaction:

$\equiv \mathrm{Al}-\mathrm{OH}+\mathrm{HCO}_{3}{ }^{-}+\mathrm{H}^{+} \rightarrow \equiv \mathrm{Al}-\mathrm{OC}(\mathrm{O}) \mathrm{OH}+\mathrm{H}_{2} \mathrm{O}$

Since ATR spectra would indicate that the surface complex is deprotonated, the following concurrent adsorption reaction equation were proposed on aged $\gamma$-alumina surfaces [54]:

$\equiv \mathrm{Al}-\mathrm{OH}+\mathrm{HCO}_{3}^{-} \rightarrow \equiv \mathrm{Al}-\mathrm{OC}(\mathrm{O}) \mathrm{O}^{-}+\mathrm{H}_{2} \mathrm{O}$

$\equiv \mathrm{Al}-\mathrm{OH}+\mathrm{H}^{+} \rightarrow \equiv \mathrm{Al}-\mathrm{OH}_{2}^{+}$

On goethite, the singly coordinated surface groups would concurrently react with bicarbonate ions and protons [61]:

$\equiv \mathrm{Fe}-\mathrm{OH}^{0.5-}+\mathrm{HCO}_{3}{ }^{-} \rightarrow \equiv \mathrm{Fe}-\mathrm{OC}(\mathrm{O}) \mathrm{O}^{1.5-}+\mathrm{H}_{2} \mathrm{O}$

$\equiv \mathrm{Fe}-\mathrm{OH}^{0.5-}+\mathrm{H}^{+} \rightarrow \equiv \mathrm{Fe}-\mathrm{OH}_{2}{ }^{0.5+}$

\section{Phosphate}

Phosphate sorption was first studied by CIR-FTIR in goethite slurries [52], then by ATR in ferrihydrite suspensions [27] and on $\mathrm{TiO}_{2}[26,32,48,64]$ or $\mathrm{SiO}_{2}[26]$ thin layers. Spectra of phosphate solutions for different $\mathrm{pH}$ were recorded, and the stretching frequencies are listed in table 6 . 
Table 6. Positions of peak maxima of dissolved phosphate and symmetry of possible surface complexes

\begin{tabular}{|c|c|c|c|c|c|c|}
\hline \multicolumn{2}{|l|}{ Species } & \multirow[t]{2}{*}{ Symmetry } & \multicolumn{4}{|c|}{ IR active bands of solute species $\left(\mathrm{cm}^{-1}\right)$} \\
\hline adsorbed* & solution & & & & & \\
\hline outer sphere $\mathrm{PO}_{4}^{3-}$ & $\mathrm{PO}_{4}{ }^{3-}$ & $\mathrm{T}_{\mathrm{d}}$ & & 1006 & & \\
\hline$(\mathrm{MO}) \mathrm{P}(\mathrm{O}) \mathrm{O}$ & $\mathrm{HPO}_{4}{ }^{2-}$ & $C_{0}$ & $847-850$ & 989 & 1077 & \\
\hline$(\mathrm{MO})_{3} \mathrm{PO}$ & $\mathrm{H}_{3} \mathrm{PO}_{4}$ & $\mathrm{C}_{3 \mathrm{v}}$ & 890 & 1006 & $1174-1179$ & \\
\hline$(\mathrm{MO})_{2} \mathrm{P}(\mathrm{O}) \mathrm{O}$ & $\mathrm{H}_{2} \mathrm{PO}_{4}^{-}$ & $\mathrm{C}_{2 \mathrm{v}}$ & $870-874$ & 940 & $1074-1075$ & $1155-1160$ \\
\hline $\begin{array}{l}(\mathrm{MO}) \mathrm{P}(\mathrm{O})(\mathrm{OH}) \mathrm{O} \\
(\mathrm{MO}) \mathrm{P}(\mathrm{O})(\mathrm{OH})_{2} \\
(\mathrm{MO})_{2} \mathrm{P}(\mathrm{O}) \mathrm{OH}\end{array}$ & & $\mathrm{C}_{\mathrm{s}}[32]$ & & & & \\
\hline $\begin{array}{l}(\mathrm{MO})_{2} \mathrm{P}(\mathrm{OH})_{2} \\
(\mathrm{MO}) \mathrm{P}(\mathrm{O})_{2} \mathrm{OH} \\
{\left[\mathrm{MOH}_{2}^{+}\right]_{---}}\end{array}$ & & & & & & \\
\hline $\begin{array}{c}{\left[(\mathrm{MO}) \mathrm{PO}_{3}\right]} \\
{\left[\mathrm{MOH}_{2}^{+}\right]---} \\
{\left[(\mathrm{MO}) \mathrm{P}(\mathrm{O})_{2} \mathrm{OH}\right]} \\
{\left[\mathrm{MOH}_{2}^{+}\right]---} \\
\left.\left[(\mathrm{MO}) \mathrm{P}(\mathrm{OH})_{2} \mathrm{O}\right)\right]\end{array}$ & & $\begin{array}{c}\mathrm{C}_{2 \mathrm{v}} \text { or lower } \\
{[27]}\end{array}$ & & & & \\
\hline
\end{tabular}

* charge of the surface complexes are not indicated [27,32,52], --- stands for the bond

between hydrogen of hydroxyl and oxygen of phosphate complex [27]

$\mathrm{PO}_{4}{ }^{3-}$ species show a single degenerated $v_{3}$ asymmetrical vibration and there is no activation of the $v_{1}$ (symmetric stretching) vibration [27]. For $\mathrm{HPO}_{4}{ }^{2-}$ an $\mathrm{H}_{3} \mathrm{PO}_{4}$ species, $v_{3}$ splits into two frequencies (respectively 1077, 989 and 1174-1179, $1006 \mathrm{~cm}^{-1}$ ) and $v_{1}$ band is activated (847-850 and $\left.890 \mathrm{~cm}^{-1}\right)$. A reduction in the symmetry occurs for $\mathrm{H}_{2} \mathrm{PO}_{4}^{-}$, leading to three bands for $v_{3}$, along the activated $v 1$ band. The possible surface inner-sphere complexes are numerous and their symmetry is mainly $\mathrm{C}_{2 \mathrm{v}}$ or lower, leading to four vibrational peaks. Tejedor-Tejedor and Anderson [52], Arai and Sparks [27] and Gong [26] are tried to deduce the geometry of surface complexes from the spectra. On goethite [52] (Fig. 5), the spectra of phosphate sorbed is hindered by the stronger bands of lattice goethite groups at 894 and 800 
$\mathrm{cm}^{-1}$ which prevents measurement at wavenumbers below $940 \mathrm{~cm}^{-1}$.
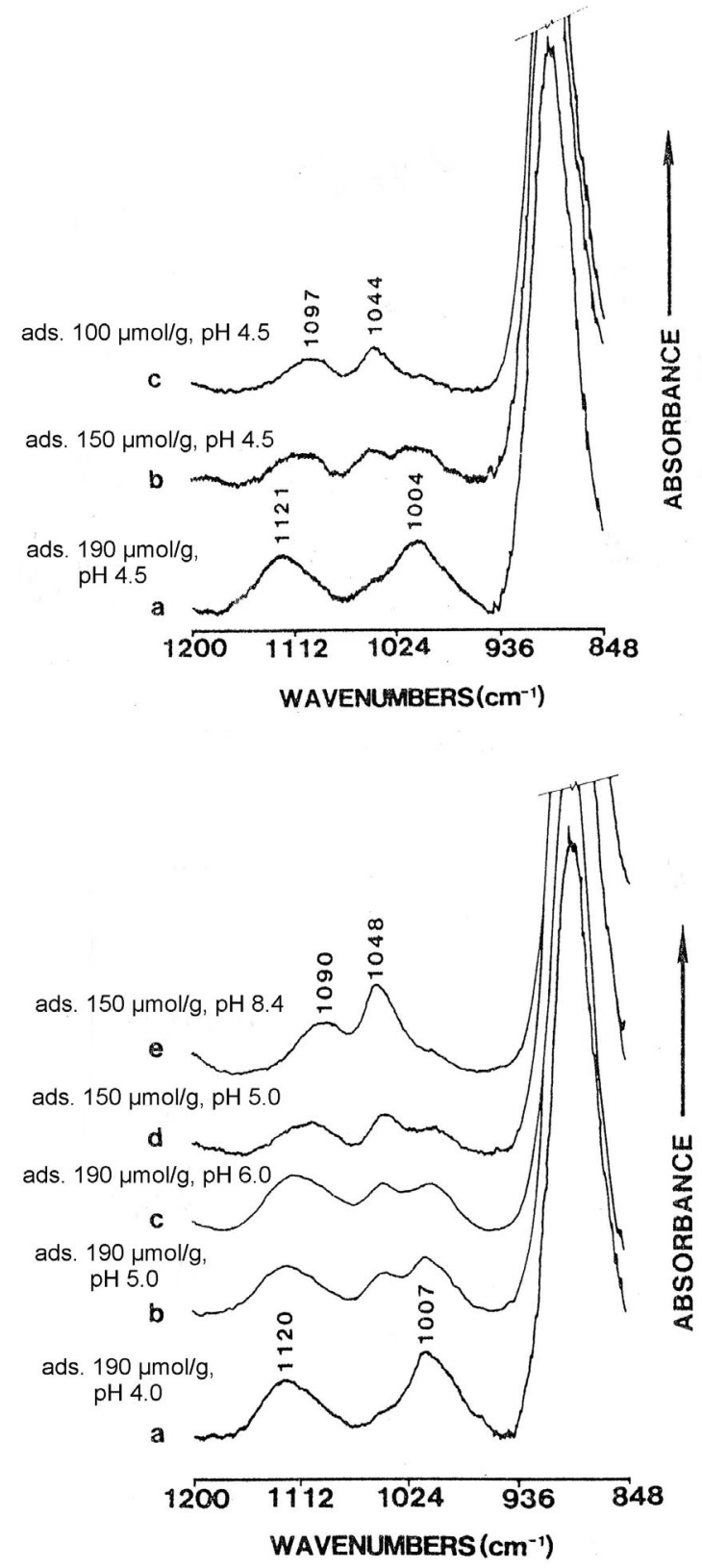

Fig. 5. Influence of phosphate surface coverage (top) and $\mathrm{pH}$ (bottom) on the CIR-FTIR spectra of phosphate sorbed on goethite (reprinted from Langmuir 6, M.A. Tejedor-Tejedor and M.I. Anderson, Protonation of phosphate on the surface of goethite as studied by CIRFTIR and electrophoretic mobility, pp602-611, copyright 1990, with permission from American Chemical Society [52]). 
The authors [52] have noted it is difficult to safely deduce the surface complex structure from the spectral results alone. They have shown the existence of three sets of bands: (I) 1123, 1006 and $982 \mathrm{~cm}^{-1}$, (II) 1096 and $1044 \mathrm{~cm}^{-1}$ and (III) 1025 and $1001 \mathrm{~cm}^{-1}$, they respectively attributed to $(\mathrm{XO})_{3} \mathrm{PO},(\mathrm{XO})_{2} \mathrm{PO}_{2}$ and $(\mathrm{XO}) \mathrm{PO}_{3}(\mathrm{X}=\mathrm{H}$ or $\mathrm{Fe})$ by comparison with spectra of aqueous phosphate whose frequencies decrease from $(\mathrm{HO})_{3} \mathrm{PO},(\mathrm{HO})_{2} \mathrm{PO}_{2}{ }^{-}$to $(\mathrm{HO}) \mathrm{PO}_{3}{ }^{2-} . \mathrm{A}$ criterion based on the $\mathrm{P}=\mathrm{O}$ stretching was used to identify the first two surface complexes: the frequency of $v_{\mathrm{P}=\mathrm{O}}$ in $(\mathrm{HO})_{3} \mathrm{P}=\mathrm{O}$ is $1174 \mathrm{~cm}^{-1}$, and the higher band of $(\mathrm{I})$ is low enough to correspond to a bidentate $(\mathrm{FeO})_{2}(\mathrm{HO}) \mathrm{PO}$ species. Thus (II) is attributed to $(\mathrm{FeO})(\mathrm{OH}) \mathrm{PO}_{2}$. On ferrihydrite, Arai and Sparks [27] decompose their spectra with three Gaussians (1088, 1021 and $952 \mathrm{~cm}^{-1}$ ), whose distributions resemble those of $\mathrm{H}_{2} \mathrm{PO}_{4}^{-}$. Since no significant change in the position was seen in $\mathrm{D}_{2} \mathrm{O}$, a nonprotonated complex $(\mathrm{FeO})_{2} \mathrm{PO}_{2}$ is deduced. On $\mathrm{TiO}_{2}$, Gong [26] sorted the bands in the spectra into two groups: (I) $1115,1055,972$ and $915 \mathrm{~cm}^{-1}$ and (II) $1008 \mathrm{~cm}^{-1}$. The single band (II) resembles the spectrum of $\mathrm{PO}_{4}{ }^{3-}$ and is attributed to an outer sphere complex. The former group is similar to the spectra of $(\mathrm{HO})_{2} \mathrm{PO}_{2}^{-}(1155$, 1075,940 and $874 \mathrm{~cm}^{-1}$ ), and the difference is consistent with a bidentate surface complex whose $v_{\mathrm{P}-\mathrm{O}}$ (upper two frequencies) is lower since $\mathrm{P}-\mathrm{OTi}$ is stronger than $\mathrm{P}-\mathrm{OH}$, and $\mathrm{v}_{\mathrm{P}-\mathrm{OH}}$ (lower two frequencies) is higher since TiOP-O is weaker than HOP-O. On the same oxide, Connor and McQuillan [32] have fitted their spectra by two sets of four bands: (I) 1085, 1038, 970 and $890 \mathrm{~cm}^{-1}$ at high $\mathrm{pH}$ and (II) $1109,1025,936$ and $890 \mathrm{~cm}^{-1}$ at low $\mathrm{pH}$ but this have not allowed them to conclusively identify the adsorbed species. As shown by this synthesis and as noticed by Connor and McQuillan [32], "the complexity of the band fitting for this system [oxide/phosphate] somewhat reduce the confidence in the conclusions reached from the derived data". In order to obtain further information on the stability of monodentate and bidentate surface complexes, the adsorption of substituted phosphates was carried out [32]. nbutyl phosphate $\left(\mathrm{BuP}(\mathrm{O}) \mathrm{O}_{2}{ }^{2-}\right)$ was adsorbed whereas dimethyl phosphate $\left(\mathrm{Me}_{2} \mathrm{P}(\mathrm{O}) \mathrm{O}^{-}\right)$, 
whose alkyl groups prevent it to form a bidentate complex with the surface, showed no adsorption onto $\mathrm{TiO}_{2}$. The results of this experiment suggest that monodentate binding of phosphate species to $\mathrm{TiO}_{2}$ surface is not viable. Such experiments with other substituted inorganic anions (methyl sulfate,...) could bring some direct information of the binding of the inorganic ions.

\section{Indifferent ions}

Numerous studies have dealt with the surface charge of inorganic colloids and particles, and with the methods used to obtain information. The surface charge created by the protonation/deprotonation of the hydroxyl groups for various $\mathrm{pH}$ is balanced by the ions present in the solution, creating a diffuse layer whose thickness is less than $3 \mathrm{~nm}$ for media whose ionic strength is higher than $0.01 \mathrm{M}$ [1]. Thus, the evolution of the amount of these ions in function of the $\mathrm{pH}$ mirrors the surface charge of the solid. The use of IR active ions have allowed to McQuillan's group ([22] and references herein) to carry out surface titrations by internal reflection spectroscopy (STIRS). Solutions of tetramethylammonium perchlorate $\left(\mathrm{TMA}^{+} \mathrm{ClO}_{4}^{-}\right) 5 \mathrm{mM}$ whose $\mathrm{pH}(2.3-11.7)$ was controlled by $\mathrm{HClO}_{4}$ and $\mathrm{TMA}$ hydroxide were used to study $\mathrm{TiO}_{2}$ [22] and chromium (III) oxy-hydroxide [24] films. Characteristic bands occurs at $1485 \mathrm{~cm}^{-1}$ (antisymmetric $\mathrm{CH}_{3}$ deformation of $\mathrm{TMA}^{+}$) and $1104 \mathrm{~cm}^{-1}$ (antisymmetric $\mathrm{v}_{\mathrm{Cl}-\mathrm{O}}$ of $\mathrm{ClO}_{4}^{-}$), and the evolution of their surface excess concentrations have led to an iep at $\mathrm{pH} 5$ for $\mathrm{TiO}_{2}$. For chromium oxy-hydroxide (expected iep: 7-8.5), no TMA concentration was observed, and $\mathrm{ClO}_{4}{ }^{-}$was only seen for $\mathrm{pH}$ lower than 5 . The negative charge of the surface seems very small and another indifferent cation $\left(\mathrm{Co}(\mathrm{en}) 3^{3+}\right)$ with a higher charge was used and was detected (bands at 1585, 1470, 1164 and $1060 \mathrm{~cm}^{-1}$ ) at the surface until $\mathrm{pH}$ 10.6. For the three ions $\left(\mathrm{TMA}^{+}, \mathrm{ClO}_{4}{ }^{-}\right.$and $\left.\mathrm{Co}(\mathrm{en})_{3}{ }^{3+}\right)$, it was checked that the 
absorption bands of sorbed species are unchanged when compared with the spectra in aqueous solutions, indicating a simple electrostatic interaction with the surface. Wijnja and Schultess [54] have shown the spectra of nitrate sorbed at the alumina/water interface to illustrate this characteristics of a very weak interaction with the surface (bands at 1400 and $1348 \mathrm{~cm}^{-1}$ ). By CIR-FTIR, Tejedor-Tejedor and Anderson [53] have recorded spectra of goethite in presence of $\mathrm{ClO}_{4}{ }^{-}$and $\mathrm{NO}_{3}{ }^{-}$to determine the influence of these ions in the structuration of water. Due to the method used to correct the background (subtraction of the supernatant spectra), the quality of the spectra is lower than those shown in previously described studies $[22,24,54]$. A doublet was seen for sorbed $\mathrm{NO}_{3}^{-}\left(1398\right.$ and $\left.1346 \mathrm{~cm}^{-1}\right)$ and a band at $1095 \mathrm{~cm}^{-1}$ with a shoulder at $1164 \mathrm{~cm}^{-1}$ for $\mathrm{ClO}_{4}^{-}$. The spectra of sorbed nitrate is the same as nitrate in solution [54] but the authors [53] expected only one band at $1390 \mathrm{~cm}^{-1}$ according to its $\mathrm{D}_{3 \mathrm{~h}}$ symmetry, and explain the difference by the existence of $\mathrm{Na}^{+}: \mathrm{NO}_{3}{ }^{-}$ion pairs in solution.

\section{Others inorganic ions ( $\mathrm{Se}, \mathrm{As}, \mathrm{B}, \mathrm{S}_{2} \mathrm{O}_{3}{ }^{2-}$ )}

The adsorption of other inorganic ions on oxides was studied, but with few published works for each of them.

Thus, Degenhardt and McQuillan [24] showed spectra of $\mathrm{S}_{2} \mathrm{O}_{3}{ }^{2-}$ adsorbed onto a chromium oxy-hydroxide layer. The free thiosulfate ion has a $\mathrm{C}_{3 \mathrm{v}}$ symmetry, and bands were observed at $1115 \mathrm{~cm}^{-1}$ (antisymmetric $v_{\mathrm{S}-\mathrm{O}}$ ) and $996 \mathrm{~cm}^{-1}$ (symmetric $v_{\mathrm{S}-\mathrm{O}}$ ). Thiosulfate adsorption was detected below pH 8 (a band at $1104 \mathrm{~cm}^{-1}$ with a shoulder at $1140 \mathrm{~cm}^{-1}$, and a band at 994 $\mathrm{cm}^{-1}$ ), leading to the conclusion that the adsorption is predominantly ionic [24].

Su and Suarez [29] have studied borate adsorption on amorphous aluminum and iron hydroxides. A lack of published IR data on boric acid solution have led the authors to analyze aqueous boric acid as a function of $\mathrm{pH}(7-11)$ and total $\mathrm{B}$ concentration. Tetrahedral $\mathrm{B}(\mathrm{OH})_{4}{ }^{-}$ 
anion at $\mathrm{pH} 11\left(\mathrm{pKa} \mathrm{B}(\mathrm{OH})_{3} / \mathrm{B}(\mathrm{OH})_{4}{ }^{-}=9.14[21]\right)$ is characterized by a broad band at 1170 $\mathrm{cm}^{-1}$ (B-OH bending) and a band at $955 \mathrm{~cm}^{-1}$ (asymmetric stretching). For $\mathrm{B}(\mathrm{OH})_{3}$ at $\mathrm{pH} 7$, two bands at 1410 and $1148 \mathrm{~cm}^{-1}$ are seen, respectively assigned to B-O asymmetric stretching and $\mathrm{B}-\mathrm{OH}$ in plane bending. The spectra of $\mathrm{Al}(\mathrm{OH})_{3}$ paste at $\mathrm{pH} 7$ with adsorbed $\mathrm{B}$ indicate trigonal boron environment with frequencies (1420 and $\left.1280 \mathrm{~cm}^{-1}\right)$ higher if compared to the boric acid solutions. The strengthening of $\mathrm{O}-\mathrm{B}$ and $\mathrm{B}-\mathrm{OH}$ bonds in the surface complex $\equiv \mathrm{Al}-\mathrm{O}-\mathrm{B}(\mathrm{OH})_{2}$ would explain this frequency evolution. At $\mathrm{pH} 10$, two bands at 1412 and $1266 \mathrm{~cm}^{-1}$ were recorded, with a raising baseline from 1500 to $1200 \mathrm{~cm}^{-1}$. In the range 1000-900 $\mathrm{cm}^{-1}$, a strong band interference with Al-O bond from the solid occurs and prevents from recording the asymmetric stretching of $\mathrm{B}(\mathrm{OH})_{4}{ }^{-}\left(955 \mathrm{~cm}^{-1}\right)$. However, the similarity between this spectrum with those of boron adsorbed at $\mathrm{pH} 7$ indicates that the adsorption of the neutral $\mathrm{B}(\mathrm{OH})_{3}$ species would be preferred, due to the charge repulsion (iep of $\mathrm{Al}(\mathrm{OH})_{3}=9.3$ [29]) encountered by $\mathrm{B}(\mathrm{OH})_{4}{ }^{-}$ion. On amorphous $\mathrm{Fe}(\mathrm{OH})_{3}$ complexes spectra were recorded after B adsorption, with bands at 1400, 1293, 1257 and $985 \mathrm{~cm}^{-1}$ at $\mathrm{pH}$ 7, and 1394, 1334, 1242 and $962 \mathrm{~cm}^{-1}$ at $\mathrm{pH} \mathrm{10.} \mathrm{Thus,} \mathrm{both} \mathrm{trigonal} \mathrm{and} \mathrm{tetragonal} \mathrm{boron}$ species would be present on the mineral surfaces, maybe resulting of a surface-promoted polymerization of boron species, since boric acid forms a series of polyanions in solution. The same authors [4] have studied by ATR the sorption of selenate $\left(\mathrm{SeO}_{4}{ }^{2-}\right)$ and selenite $\left(\mathrm{SeO}_{3}{ }^{2-}\right)$ on amorphous $\mathrm{Fe}(\mathrm{OH})_{3}$ at $\mathrm{pH}$ 5. Selenate species in solution are characterized by a band at $872 \mathrm{~cm}^{-1}$ (asymmetric stretching of Se-O bond). Due to its $\mathrm{T}_{\mathrm{d}}$ symmetry, its complexation by surface groups would lead to a decrease of its symmetry and to a splitting of the triply degenerated band (see detailed explanation for sulfate ions). A complex band (maximum at $879 \mathrm{~cm}^{-1}$ with shoulders at 890 and $824 \mathrm{~cm}^{-1}$ ) was observed for selenate sorbed on $\mathrm{Fe}(\mathrm{OH})_{3}$, indicating an inner-sphere complex. The free $\mathrm{SeO}_{3}{ }^{2-}$ ion has a $\mathrm{C}_{3 \mathrm{v}}$ symmetry, but its high $\mathrm{pK}_{\mathrm{a} 2}\left(7.31\right.$ [21]) leads to a mixture with $\mathrm{HSeO}_{3}{ }^{-}$in the $\mathrm{pH}$ range where its sorption on 
$\mathrm{Fe}(\mathrm{OH})_{3}$ was observed $(\mathrm{pH}<10)$. Thus, selenite aqueous solutions exhibit bands at 851,822 and $731 \mathrm{~cm}^{-1}(\mathrm{pH} 8)$, or 849 and $825 \mathrm{~cm}^{-1}(\mathrm{pH} \mathrm{5})$. The spectrum of selenite sorbed on $\mathrm{Fe}(\mathrm{OH})_{3}$ at $\mathrm{pH} 5$ is characterized by two broad bands at 844 and $750 \mathrm{~cm}^{-1}$, too weak to allow the identification of the sorbed species. Peak and Sparks [55] have recorded the spectra of selenate sorbed onto hematite in $\mathrm{D}_{2} \mathrm{O}$ (Fig. 6) and the $v_{3}$ splitting to two peaks at 880 and 850 $\mathrm{cm}^{-1}$ is described, with the $v_{1}$ peak at $820 \mathrm{~cm}^{-1}$ becoming active. A monodentate selenate surface complex was assumed from this spectra [55].

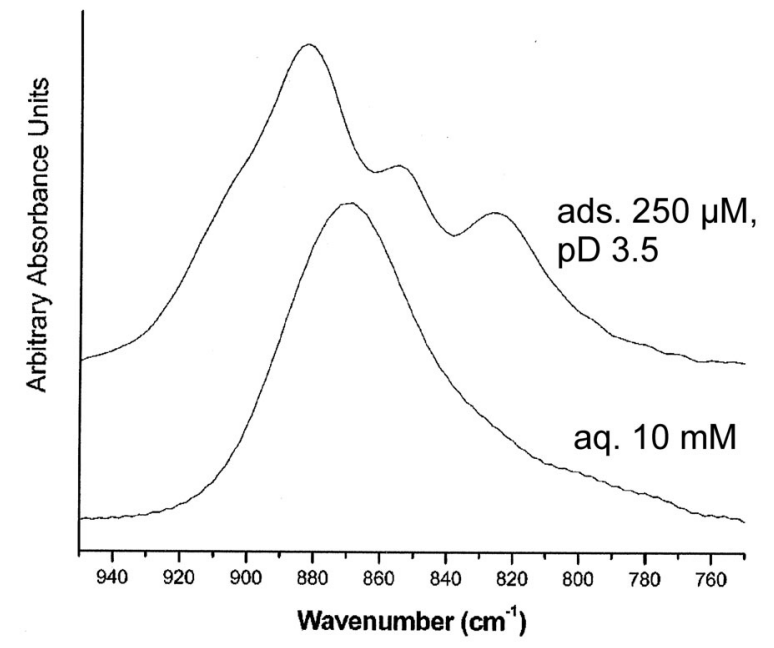

Fig. 6. ATR-FTIR spectra of selenate. ads refers to species adsorbed on hematite and aq. to aqueous $\mathrm{SeO}_{4}{ }^{2-}$ (reprinted from Environ. Sci. Technol. 36, D. Peak, and D.L. Sparks, Mechanisms of selenate adsorption on iron oxides and hydroxides, pp 1460-1466, copyright. 2002, with permission from American Chemical Society [55]).

Arsenate ion $\left(\mathrm{AsO}_{4}{ }^{3-}\right)$ sorption onto amorphous ferric oxide was studied by ATR [28]. The acidity constants of arsenic acid are 2.2, 6.9 and 11.5. Pure solution of arsenate ions are respectively characterized by bands at $792 \mathrm{~cm}^{-1}\left(\mathrm{AsO}_{4}{ }^{3-}\right), 858 \mathrm{~cm}^{-1}\left(\mathrm{HAsO}_{4}{ }^{2-}\right)$ and 908,878 and $738 \mathrm{~cm}^{-1}\left(\mathrm{H}_{2} \mathrm{AsO}_{4}^{-}\right)$[28]. Arsenate sorbed on a film of $\mathrm{Fe}(\mathrm{OH})_{3}$ at various $\mathrm{pH}$ have shown a band at $800-825 \mathrm{~cm}^{-1}$ (shift toward lower frequency for higher $\mathrm{pH}$ values). From these 
spectra and isotherm plots, a possible structure of bidentate, or weak bidentate via protonated oxide bridges was indicated [28].

\section{Ternary complexes $\equiv \mathrm{Fe}-\mathrm{XO}_{\mathrm{n}}{ }^{\mathrm{m}-}-\mathrm{M}^{\mathrm{X}}$}

By combining results from ATR and EXAFS, information has been obtained on ternary systems goethite-sulfate- $\mathrm{Pb}(\mathrm{II})$ [30,60], goethite-carbonate- $\mathrm{Pb}(\mathrm{II})$ [34] and hematitecarbonate-U(VI) [36]. The main question is about the type of complex, characterized by the bridging ion, i.e. $\equiv \mathrm{FeO}-\mathrm{XO}_{\mathrm{n}}{ }^{\mathrm{m}-}-\mathrm{M}^{\mathrm{X}}$ or $\equiv \mathrm{FeO}-\mathrm{M}^{\mathrm{X}}-\mathrm{XO}_{\mathrm{n}}{ }^{\mathrm{m}-}$. For the goethite-sulfate- $\mathrm{Pb}(\mathrm{II})$ system, the addition of $\mathrm{M}^{\mathrm{X}}$ ions in the suspension increases the signal of the oxoanion and modifies the spectra. Thus, the subtraction of the spectra recorded with and without metal leads to the spectrum of the sulfate bonded with the metal ion.
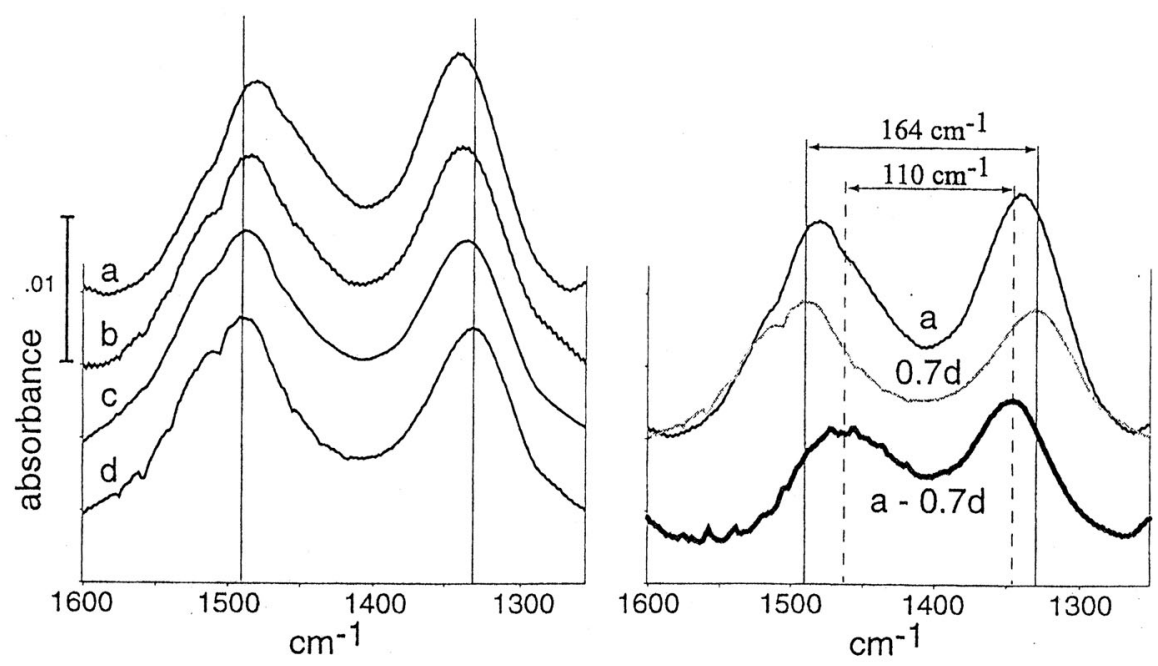

Fig. 7. ATR-FTIR spectra showing the effects of $\mathrm{Pb}$ on the $v_{3}$ vibrations of carbonate sorbed to goethite. $\mathrm{Pb}$ surface coverages: $2,1,0.5$ and $0 \mu \mathrm{mol} / \mathrm{m}^{2}$ for spectra a-d respectively. Spectrum at bottom right (bold) shows subtraction of $\mathrm{Pb}$-free spectrum to highest coverage spectrum (reprinted from J. Colloid Interface Sci. 225, J.D. Ostergren, G.E. Brown, G.A. Parks and P. Persson, Inorganic ligand effects on $\mathrm{Pb}(\mathrm{II})$ sorption to goethite $(\alpha-\mathrm{FeOOH})$. II. Sulfate, pp483-493, copyright 2000, with permission from Elsevier [34]). 
Ostergren et al. [60] identified the ternary complex as $(\equiv \mathrm{Fe}-\mathrm{O})_{2} \mathrm{~Pb}-\mathrm{OSO}_{3}$, which is in agreement with the following similar study by Elzinga et al. [30].

A similar complex was found for the system goethite-carbonate- $\mathrm{Pb}(\mathrm{II})$, i.e. $(\equiv \mathrm{Fe}-\mathrm{O}){ }_{2} \mathrm{~Pb}-\mathrm{OCO}_{2}$ [34] (Fig. 7). For the system hematite-carbonate-U(VI), the data from ATR and EXAFS would be fitted by a $(\equiv \mathrm{Fe}-\mathrm{O})_{2} \mathrm{UO}_{2}-\left(\mathrm{CO}_{3}\right)_{\mathrm{x}}$ complex, where $0 \leq \mathrm{x} \leq 2[36]$.

Another case is the coadsorption of $\mathrm{Ca}^{2+}$ and phosphate on $\mathrm{TiO}_{2}[64]$ where the presence of $\mathrm{Ca}^{2+}$ ions leads to an increased amount of adsorbed phosphate. This additional adsorbed phosphate would come from the formation of surface complex consisting in a bidentate phosphate bound to amorphous $\mathrm{TiO}_{2}$, with $\mathrm{Ca}^{2+}$ binding to the already adsorbed phosphate, and with an additional electrostatically adsorbed phosphate:

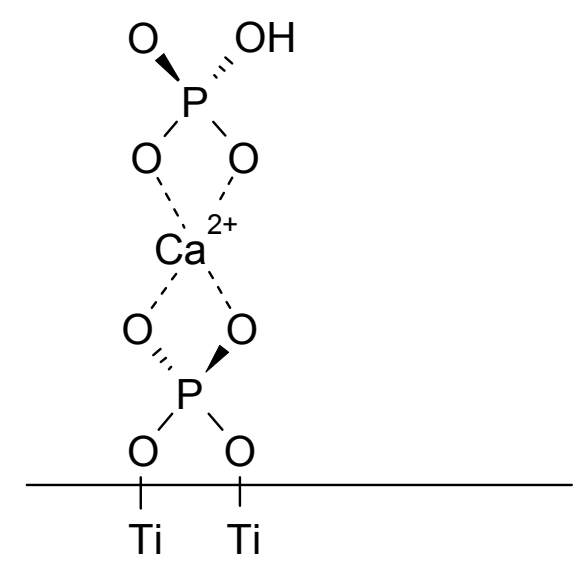

This conclusion is based on the difference between adsorption strength of $\mathrm{Ca}^{2+}$ and phosphate ions (adsorption of $\mathrm{Ca}^{2+}$ is weaker than phosphate), and on the decrease of the spectra structure in $\mathrm{Ca}^{2+} /$ phosphate sorption experiments, indicating a change of the adsorbed phosphate symmetry to $\mathrm{C}_{3 \mathrm{v}}$ (correlated to the electrostatically adsorbed $\mathrm{HPO}_{4}{ }^{3-}$ ). Experiments performed in the same conditions $\left(\mathrm{CaCl}_{2} 3.5 \times 10^{-3} \mathrm{M}, \mathrm{K}_{2} \mathrm{HPO}_{4} 3.8 \times 10^{-3} \mathrm{M}\right.$, pH 6.5) with crystalline $\mathrm{TiO}_{2}$ (predominantly anatase), have shown that the precipitation of brushite $\left(\mathrm{CaHPO}_{4} .2 \mathrm{H}_{2} \mathrm{O}\right)$ occurs. The difference between amorphous and crystalline $\mathrm{TiO}_{2}$ towards $\mathrm{Ca}^{2+} /$ phosphate system is an important result for the knowledge of the growth of bone on titanium implants [64]. 


\section{CONCLUSIONS AND FUTURE DIRECTIONS}

The cited articles about the use of ATR-FTIR to study oxide/solution interface illustrate the possibility of this method to obtain in situ information on the sorbed species. It allows to bring elements to improve the comprehension of sorption mechanisms of some inorganic ions, differentiating between OS and IS complexes for example. Interpretation of the spectra to obtain information on IS complexation is more tricky due to the different possibilities of the spectra decomposition since reference spectra are difficult to obtain. This step is even more complex for ions able to sorbs with a lot of different geometries (phosphate for example). However, this method has several advantages suitable for the current problems in the sorption field: an in situ analysis, a sensitivity allowing the study of low surface coverage, and the possibility of time-resolved study. For five years, less than 20 articles have mentioned the use of ATR-FTIR to study the sorption of inorganic ions onto oxy-hydroxides amongst dozens of studies in this field. It illustrates the recentness of this technique and future developments should focus on some points that were less studied until now. Thus, ATR results have been hardly used to refine sorption modeling, even if it was an objective of the first studies [12]. The ionic strength is a usual parameter studied in batch experiments due to its effect on the OS sorption, but its influence on ATR spectra have been hardly investigated. When a mixture of OS and IS complexes is expected, it would be a way to help the decomposition of the spectra. Another point needing further investigation in studies using colloid layer onto ATR crystals is the effect of layer deposition protocol. The relation between amount of deposited colloid and signal intensity of sorbed species remains undocumented. The desorption of species from a colloid layer was rarely studied whereas a lack of reversibility was observed by Connor and McQuilllan [32]. This behavior may result from the structure of the colloid film whose particles agglomerate to form micropores, what differs from well-stirred suspensions used in batch experiments. It would render difficult the comparison between sorption 
experiments performed on a coated ATR element or on suspensions with a batch protocol. Thus, this point need to be clarified and new works about the characterization of the deposited layer would allow to define the limit of the use of the results from ATR.

\section{ACKNOWLEDGEMENTS}

The author thanks Sylvie Noinville (LADIR, Thiais, France) for assistance with ATR-FTIR technique, Catherine Droniou (CECM) for her help in getting bibliographic references, Michel Fédoroff (CECM) and A. James McQuillan (University of Otago, Dunedin, New Zealand) for discussion and helpful comments on a preliminary manuscript. Financial support from the Institut des Sciences Chimiques Seine-Amont (CNRS-IFR 1780) is gratefully acknowledged. 


\section{REFERENCES}

[1] W. Stumm, Chemistry of the solid-water interface, Wiley, New York, 1992.

[2] J.F. Boily, in P. Somasundaran (Ed.), Encyclopedia of Surface and Colloid Science, Dekker, New York, 2002, p.3223.

[3] J. Lützenkirchen, in P. Somasundaran (Ed.), Encyclopedia of Surface and Colloid Science, Dekker, New York, 2002, p.5028.

[4] C. Su and D.L. Suarez, Soil Sci. Soc. Am. J. 64 (2000) 101.

[5] K.F. Hayes, A.L. Roe, G.E. Brown, K.O. Hodgson, J.O. Leckie, and G.A. Parks, Science 238 (1987) 783.

[6] D. Banerjee and H.W. Nesbitt., Geochim. Cosmochim. Acta 63 (1999) 1671.

[7] R. Drot, E. Simoni, M. Alnot and J.J. Ehrhardt, J. Coll. Interface Sci. 205 (1998) 410.

[8] J.R. Bargar, G.E. Brown, and G.A. Parks, Geochim. et Cosmochim. Acta 62 (1998) 193.

[9] Y. Arai, E.J. Elzinga , and D.L. Sparks, J. Colloid Interface Sci. 235 (2001) 80.

[10] C. Papelis, G.E. Brown, G.A. Parks and J.O. Leckie, Langmuir 11 (1995) 2041.

[11] D. Peak, R.G. Ford and D.L. Sparks, J. Colloid Interface Sci. 218 (1999) 289.

[12] S.H. Hug, J. Colloid Interface Sci. 188 (1997) 415.

[13] T. Sugimoto, and Y. Wang, J. Colloid Interface Sci. 207 (1998) 137.

[14] F.M. Mirabella, in F.M. Mirabella (Ed.), Internal Reflexion Spectroscopy, Dekker, New York, 1993, p.17.

[15] J.W. Strojek, J. Mielczarski, and P. Nowak, Adv. Colloid Interf. Sci. 19 (1983) 309.

[16] S.J. Hug, and B. Sulzberger, Langmuir 10 (1994) 3587.

[17] A.R. Hind, S.K. Bhargava, and A. McKinnon, Adv. Colloid Interf. Sci. 93 (2001) 91.

[18] J. Madejova, Vib. Spectrosc. 944 (2002) 1. 
[19] J.P. Coates, in F.M. Mirabella (Ed.), Internal Reflexion Spectroscopy, Dekker, New York, 1993, p.53.

[20] L.D. Tickanen, M.I. Tejedor-Tejedor, and M.A.Anderson, Langmuir 7 (1991) 451.

[21] Handbook of Chemistry and Physics, $79^{\text {th }}$ ed.; D.R. Lide ( Ed.),CRC Press, Boca Raton, 1998.

[22] A.J. McQuillan, Advanced Materials 13 (2001) 1034.

[23] J.D. Peak and D.L. Sparks, Kinetics of oxyanion sorption on metal oxides: a timeresolved ATR-FTIR spectroscopic study, Proc. 5th Intern. Conf. on the Biogeochem. of Trace Metals, Vienna, 1999, p344.

[24] J. Degenhardt and A.J. McQuillan, Langmuir 15 (1999) 4595.

[25] H. Wijnja and C.P. Schulthess, J. Colloid Interface Sci. 229 (2000) 286.

[26] W. Gong, Int. J. Miner. Process. 63 (2001) 147.

[27] Y. Arai, Yand D.L. Sparks, J. Colloid Interface Sci. 241 (2001) 317.

[28] A.J. Roddick-Lanzilotta, A.J. McQuillan, A.J. and D. Craw, Appl. Geochem. 17 (2002) 445

[29] C. Su and D.L. Suarez, Environ. Sci. Technol. 29 (1995) 302.

[30] E.J. Elzinga, D. Peak and D.L. Sparks, Geochim. Cosmochim. Acta 14 (2001) 2219.

[31] C. Su and D.L. Suarez, Clays Clay Miner. 45 (1997) 814.

[32] P.A. Connor and A.J. McQuillan, Langmuir 15 (1999) 2916.

[33] M. Villalobos and J.O. Leckie, J. Colloid Interface Sci. 235 (2001) 15.

[34] J.D. Ostergren, T.P. Trainor, J.R. Bargar, G.E. Brown and G.A. Parks, J. Colloid Interface Sci. 225 (2000) 466.

[35] J.J. Lenhardt, J.R. Bargar and J.A. Davis, J. Colloid Interface Sci. 234 (2001) 448.

[36] J.R. Bargar, R. Reitmeyer, and J.A. Davis, Environ. Sci. Technol. 33 (1999) 2481.

[37] P.A. Connor, K.D. Dobson and A.J. McQuillan, Langmuir 11 (1995) 4193. 
[38] M. Janotta, M. Karlowatz, F. Vogt and B. Mizaikoff, Anal. Chim. Acta 496 (2003)

[39] B.J. Ninness, D.W. Bousfield and C.P. Tripp, Appl. Spectrosc. 55 (201) 655

[40] D.A. Dzombak and F.M.M. Morel, Surface Complexation Modeling: Hydrous Ferric Oxide, Wiley, New York, 1990.

[41] W. Szczepaniak and H. Koscielna, Anal. Chim. Acta 470 (2002) 263.

[42] G. Lefèvre, A. Walcarius, J.J. Ehrhardt, and J. Bessière, Langmuir 16 (2000), 4519.

[43] R.P.J.J. Rietra, T. Hiemstra, and W.H. Van Riemsdijk, J. Colloid Interf. Sci. 229 (2000) 199.

[44] A.E. Regazzoni, M.A. Blesa, and A.J.G. Maroto, J. Colloid Interface Sci. 122 (1988), 315.

[45] R. Sprycha, J. Colloid Interface Sci. 102 (1984), 173.

[46] J.M. Kleijn and J. Lyklema, J. Colloid Interface Sci. 120 (1987) 511.

[47] R. Sprycha, J. Colloid Interface Sci. 127 (1989) 1.

[48] A. Michelmore, W. Gong, P. Jenkins and J. Ralston, J. Phys. Chem. Chem. Phys. 2 (2000) 2985.

[49] L. Celi, E. Barberis, and M. Franco Ajmone, Soil. Sci. 165 (2000) 657.

[50] N.F. Gray, Wat. Res. 32 (1998) 2122.

[51] Council Directive 98/83/EC on the quality of water intended for human consumption, European Union, 1998.

[52] M.I. Tejedor-Tejedor and M.A. Anderson, Langmuir 6 (1990) 602.

[53] M.I. Tejedor-Tejedor and M.A. Anderson, Langmuir 2 (1986) 203.

[54] H. Wijnja, and C.P. Schulthess, Spectrochimica Acta A 55 (1999) 861.

[55] D. Peak and D.L. Sparks, Environ. Sci. Technol. 36 (2002) 1460.

[56] P. Persson and L. Lövgren, Geochim. Cosmochim. Acta 60 (1996) 2789. 
[57] K. Nakamoto, Infrared and Raman spectra of inorganic and coordination compounds, $4^{\text {th }}$ ed., Wiley \& Sons, New York, 1986.

[58] C.G. Barraclough and M.L. Tobe, J. Chem. Soc. (1961) 1961.

[59] R.L. Parfitt, and R.S.C. Smart, Soil Sci. Soc. Am. J. 42 (1978) 48.

[60] J.D. Ostergren, G.E. Brown, G.A. Parks and P. Persson, J. Colloid Interface Sci. 225 (2000) 483.

[61] H. Wijnja, and C.P. Schulthess, Soil Sci. Soc. Am. J. 65 (2001) 324.

[62] G. Lefèvre, M. Duc, P. Lepeut, R. Caplain, and M. Fédoroff, Langmuir 18 (2002) 7530.

[63] C.P. Schulthess, K. Swanson, and H. Wijnja, Soil Sci. Soc. Am. J. 62 (1998) 136.

[64] T.K. Ronson and A.J. McQuillan, Langmuir 18 (2002) 5019. 